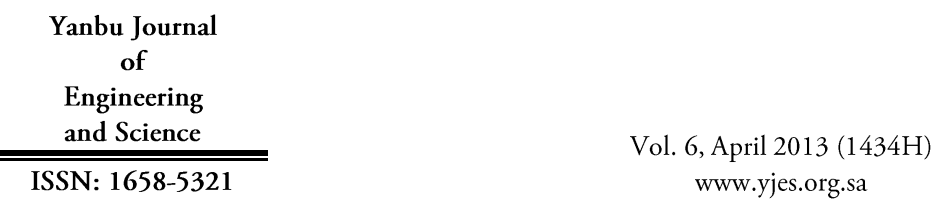

\title{
PARTICLE IMAGING VELOCIMETRY (PIV) TECHNIQUE: PRINCIPLES AND APPLICATIONS, REVIEW
}

\author{
Hassan Abdulmouti \\ Mechanical Engineering Department, Prince Mohammad Bin Fahd University, Saudi Arabia \\ E-mail: habdulmouti@pmu.edu.sa
}

\begin{abstract}
Particle Imaging Velocimetry (PIV) has been recognized as an essential and very useful technique for analyzing two- or three- dimensional complex flow fields and two-phase fluid flows. PIV techniques promise to give improved results because they provide a visual solution taking the total field into account. In addition, PIV offers many advantages for the study of fluid flow. PIV is a measuring technique that allows us to capture the flow velocity of whole flow fields in a fraction of a second. Hence, PIV has become more and more popular and it has rapidly spread in the world being recognized as the most advanced flow velocimetry because of its strong merits. Its application ranges have been expanding to measure turbulent flow, multiphase flow, internal flow of fluid machines, bioengineering, medical engineering, environmental engineering, energy engineering, development of new materials, sports science, life science, mechatronics, robotics and so on. Furthermore, PIV has been recognized as a powerful new measuring tool in thermal and fluid engineering fields including multiphase flows. Thus, PIV is a very promising powerful tool in the study of the structure of flows.

In this paper, the principles and the typically used methods of PIV measurement are summarized. The classification of PIV methods is also explained.
\end{abstract}

Keywords: Particle Imaging Velocimetry (PIV), Particle tracking Velocimetry (PTV), Computational Fluid Dynamics CFD, Flow Visualization, Multiphase Flow, Image Processing, and Bubbly Flow.

\section{INTRODUCTION}

Since ancient times, man has attempted to decorate vessels and bells with patterns of waves and firs. This might well have come from their worship of their God or superpower in nature, it is clear that even in the distant past man has observed and visualized nature with reverence.

It is well known that in the renaissance Leonardo da Vinci left some sketches of the vortical flow behind obstacles. This may be the first scientific approach to flow visualization. In the last century, natural science has made rapid progress. Indeed, an epoch-making discovery in fluid dynamics was made by $\mathrm{O}$. Reynolds through a flow visualization technique (dye-tracer method) that clarified the transition from laminar to turbulent flow to be governed by a nondimensional parameter crowned his name. Since then, flow visualization techniques have played important roles to elucidate flow phenomena. In particular they served to create new concepts such as the boundary layer by L. Prandtl (particle-suspension method) and the 
bursting mechanism in the generation of turbulence by $\mathrm{S}$. Kline ( $\mathrm{H}_{2}$-bubble method). Towards the threshold of the 21st century, and with the emergence at the horizon of a new technological frontier, our civilized society encounters various hazards related to food, water resources, energy, environment and so on. These are more or less related to fluid or flow hence, technology dealing with flow becomes more important.

Research and development activities in fluid mechanics have grown exponentially over the past several decades, with new areas of specialization continuing to be identified. Today's process engineer encounters a multitude of flow dynamics problems throughout his career, either directly in fluidhandling functions, or by inference through transport phenomena within unit operations. Furthermore, the complexity of manufacturing sets the stage for two-, and three-phase flows, non-Newtonian material processing, slurry flows, and numerous unstable and transition-type flows.

Because of the complexity of flow phenomena and the diversity of problems, engineers and scientists must be able to extend their knowledge and expertise beyond the rudimentary principles of classical fluid mechanics.

It is also to be noted that the optical method has considerably advanced the field of highspeed aerodynamics and brought about today's prosperity of the aviation industry. The laser's invention has led to revolutionary progress in optical visualization methods, creating new methods such as holography and the speckle method. Lasers are now widely used in flow visualization as light sources and as signal carriers in laser optical systems. Moreover, flow visualization is now an effective tool in the field of fluid dynamics. It differs from other methods in rendering certain properties of a flow field directly accessible to visual perception. In the history of the research of fluid dynamics, flow visualization played its part in all outstanding discoveries, since observing a flow pattern gives good idea of the whole development of the flow.

Flow visualization is basically used to gain information of the whole observed flow field. This improves the ability to qualitatively grasp the physical characteristics of phenomena, but difficulties remain in the quantitative analysis of flows.

In the last ten years, visualization has gone for many scientists from the lab to become a desktop technology. Images and 3-D renderings of data sets and mathematical models have evolved from high-priced hardware and customized software of graphics professionals to low-cost, off-the-shelf commercial software running on personal computers. As such, scientific visualization has taken its place besides mathematical modeling as an everyday means of interacting with one's data. This has significantly changed both the amount and the quality of information that scientists are able to extract from raw data, and has effectively established a new paradigm for scientific computing. In addition, new and, low-cost hardware and software technologies such as CD-ROM, digital video, and Apple's Quick Time timebased media and compression technologies have enabled large amounts of images and animated data to be easily accessible to the average researcher through the personal computer and the internet.

However, progress in visualization will not only affect the fields of engineering and physics, but also other fields such as medical science, agriculture, marine products, oceanography, meteorology and sports. 
It is strongly expected that basic science and technology in universities will contribute effectively to energize local industries and to attain high level standards of life in community and information-oriented societies.

Over the last decade, advances in computer technology have brought great and significant changes in the fields of flow visualization and experimental fluid dynamics (which is one of the basic and important engineering sciences). Particularly in the form of image processing and computer graphics, and namely computer-aided flow visualization (CAFV), where the digital image processing technique has now grown into a multi-disciplinary activity with considerable influence. These technologies are now being used to great effect for quantitative analysis in flow visualization, a capability which this field previously lacked. This development has made it also possible to visualize nonvisual information in living bodies, termed computer tomography (CT). Numerical calculation has also come to be recognized as a partner of flow visualization with regard to computational fluid dynamics (CFD). Even now we are seeing flow visualization expand to cover a range of information generally thought of as nonvisual, such as heat and mass transfer, acoustic energy flow, electromagnetic flow, etc.

In the field of fluid dynamics, CFD (computational fluid dynamics) has made a remarkable progress in these years and it is now widely used in various industrial applications. However, despite this progress in CFD, highly accurate experiments are still indispensable for better understanding of complicated flow phenomena and validate CFD software. To meet these needs, various computational methods and sophisticated instruments have been devised and developed in recent years to advance the experimental investigation of flow fields.

Particle imaging velocimtry (acronym PIV) is particularly promising, because it can instantaneously provide comprehensive and quantitative information about the whole flow field. Owing to remarkable recently progress, PIV is now developing into a very powerful tool, which may even be applied to 3dimensional flow field.

The rapid development of Particle Imaging Velocimetry (PIV) and other new fluid measurement techniques is going hand in hand with multi-media techniques and their corresponding image processing techniques. However, the PIV technique has especially been developed with the noticeable development of modern computer techniques. PIV is generally based on fluid visualization and image processing techniques. It is well known that fluid flow can be visualized by seeded particles or dye materials. The movement distances of all particles or ensembles of particle images (particle image patterns) in a whole flow field can be measured from a series of consecutive images to derive the velocity vector field. With this simple concept, an advanced tool for automated measurement of fluid flow; the velocity vector map obtained by PIV enables further extraction of physical information such as the pressure field and the vorticity field, by CFD (Computational Fluid Dynamics). A survey on PIV, Adrian [1] confirmed that PIV has rapidly advanced in developing its fundamentals and widened its applications to multiphase flows, thermal flows and turbulence structures.

Over the past decade particle image velocimetry (PIV) has undergone substantial improvements in measurement precision and reliability. Each new interrogation algorithm 
challenges the numerical precision and reliability of preceding ones.

It is also well known that PIV is now firmly established in the area of fluid mechanics as a powerful fluid dynamics tool to instantaneously measure the full-field flow velocity. Furthermore, PIV velocity measurement techniques are now well established and ready to be employed for industrial applications. A large part of recent investigations is devoted to the enhancement of the quality and resolution of these techniques (improvements of image analysis methods) and to the extraction of useful information from large amounts of data provided (improvement in data extraction methods).

On the other hand, flow visualization is extremely important for the study of flow field structures and interactions. PIV is a natural extension of visualization techniques, where velocity vectors are measured simultaneously at thousands of points with high accuracy and resolution.

In addition, PIV is particularly useful in the measurement of unsteady flows. Latent turbulent structures can be unmasked with PIV, whereas averaging techniques (like LDV or PDPA) tend to wash out structures. In periodic flows, such as in internal combustion (IC) engines, turbines, and so on, the entire flow field information can be obtained for each phase angle. Furthermore, for steady flows with complex geometry where access may be difficult, PIV can be a useful tool. Time averaged velocity and turbulence values at each point in the flow field can be obtained with PIV when a sequence of frames is analyzed. In addition, PIV can be used to study turbulence structures if a sufficient amount of data can be acquired and analyzed [2-18].
Since the personal computer, laser light systems for visualization, image processing units, and video systems have pervaded every field of engineering, also without the exception of fluid and thermal engineering fields, the techniques of particle imaging velocimetry (PIV) have been advanced quickly and they offer many advantages for the study of fluid flow because of the following merits:

1. Instantaneous whole flow field measurement.

2. Contact-free measurement.

3. Easy extraction and processing of physical information through velocity information [19].

PIV enables fluid velocities across a whole flow region to be measured at a single instant in time in whole (global) volume of interest. This instantaneous velocity profile of a given flow field is determined by first digitally recording particle (microspheres or bubble) images within the flow over multiple successive video frames and then conducting flow pattern identification and analysis of the data. PIV is also useful for understanding the detailed structure of two-phase flows.

In addition, PIV is a non-intrusive measurement technique, which can be used to study the structure of various fluid flows. Therefore, it is a superior measurement technique for studying fluid flows, its primary advantage being the ability to capture spatial velocity distributions simultaneously and noninvasively [20-23].

On the other hand, PIV is used to measure the full time varying velocity field data of particle-seeded flow fields within either a twodimensional plane or of a three-dimensional volume. Hence, PIV is used to determine the velocity fields in two and three-dimensions. It can also be used to study two-phase fluid flows if both phases can be distinguished. Thus, PIV is a very efficient measurement 
technique since it can simultaneously obtain both qualitative and quantitative spatial information about the flow field being studied. This information includes vorticity, path line, Reynolds stresses and kinetic turbulent energy, etc, while other flow measurement techniques (Laser Doppler Velocimetry, Hot Wire Anemometer...etc) only provide temporal quantitative information at a single point [2429 among others].

Particle Image Velocimetry appeared 25 years ago and since then has become an essential measurement technique in fluid mechanics laboratories in both research institutes and industry. Papers related to PIV have represented approximately half of the total papers presented in the Lisbon International Symposia on Applications of Laser Techniques to Fluid Mechanics held since [30]. This success, boosted by the progress in laser technologies as well as electronic image recording, can be explained by the large quantity of information that can be recorded instantaneously and simultaneously, for a reasonable implementation effort, compared to other measurement techniques. It is also related to the development of several commercial systems that have made the technique easily available worldwide, for a very large variety of applications, ranging from microfluidic scales ( $\sim$ a few hundred microns) to large fields $(\sim 1 \mathrm{~m})$ in wind tunnels. This spectacular development has been largely supported through collaborative networks such as EUROPIV or PIV Challenge [31-34], set up to foster international cooperation and organize worldwide comparison of algorithm performances [35].

PIV relies on fast and accurate methods to instantaneously track numerous particles suspended in the flow. These particles can be seeded with micron size and with certain physical properties so that they accurately follow the flow path lines and respond to accelerations in the flow. PIV is a promising and powerful tool to study the structure of flows in general.

Many researchers have carried out extensive model experiments by focusing on flow field structures and many kinds of visualized images using PIV technique because it is a very powerful tool, very popular and has wide applications. In addition, the development of this technique is required. Hence, the motivation of the present work is the demand to summarize and demonstrate the principle of PIV technique. The purpose of this paper is to provide a detailed course on PIV and a brief reminder of the principles of the technique, its high potential will be illustrated using some selected studies. The most significant directions of progress that this continuously evolving technique has followed recently are then present. Beyond that, the present work is concerned with proposing the classification of PIV technique and its application, since it can contribute to various improvements.

Although PIV technique has previously been described in many literatures (references), previous research projects hardly elucidated all principles of PIV technique, the classification of all PIV technique and its applications. However, in the past detailed information about these points has not been acquired. On the other hand, there are very few and limited reports on research concerning these points. Hence there is still room for more improvement to get a good reference about PIV technique. However, more exact and detailed information is required in order to understand the basics and the classification and the principle of PIV technique. In this 
relation, information on PIV technique becomes more and more important.

\section{THE PRINCIPLE OF PIV}

Previously, the method for acquiring velocities at grid points using high-density distribution patterns of particle images was referred to particle imaging velocimetry (PIV), and the method used to track each particle for low particle number densities was referred to particle tracking velocimetry (acronym PTV). In this paper, PIV is used as a general term for velocimetry using particle images. However, it is necessary to review the present PIV techniques and examine their applicability to multiphase flow systems.

PIV, which combines the techniques of flow visualization and image processing to measure the flow field velocity, has developed very quickly in recent years. It has been developed rapidly with the remarkable development of computers and image processing techniques. The technique of PIV gives information on flow velocity, temperature and density through image analysis of visualized images of various types of flows [36].

The basic principle of PIV is to measure the field flow velocity indirectly by analyzing the motion of seeded particles in the flow. Usually the size of seeded particles is very small compared to the scale of the flow, thus the velocity of each seeded particle can be considered as the velocity of the fluid where it is located. The images of the movement distances of all particles or ensembles of particles (particle image pattern) in a whole flow field can be measured from a series of consecutive images to derive the velocity vector field. The main difficulty of PIV is particle identification. High accuracy of measurement requires a sufficient number of seeded particles in the measuring volume. If the movement of the fluid in the measuring volume is complex, such as in the cases of high velocity or strong rotation, it is very difficult to identify each particle in consecutive image frames. Since the end of last decade, many algorithms for analyzing the particles in frames have been developed, such as [20-22 and 37].

It is well known that there is no general-use type of standard PIV system. Each type of PIV needs fitting hardware and software to measure a flow field. Even though many types of PIV are applied today, they still include common processes. PIV measurements consist of four stages: 1) seeding, 2) illuminating, 3) photographing and 4) image processing. For accurate PIV measurements, each stage should be rigorously performed in whole experiment. The stages of a PIV measurement are detailed as follows:

\section{1 SEEDING}

When particles have a good behavior of traceability to a fluid flow, the particle velocities usually represent the local fluid velocities. The small particles seeded in the fluid to trace its flow should (a) be distributed as homogeneous as possible in the fluid. (b) be well reflecting, (c) accurately follow the motion of the fluid, (d) not alter the properties of the fluid and its flow. Generally, the particles that satisfy the four conditions have diameters of $40-300 \mu \mathrm{m}$ and a density that makes them almost neutrally buoyant in fluid. If the seeding concentration is appropriate, it corresponds to the density of velocity vectors desired.

\section{2 ILLUMINATING}

In two-dimensional PIV measurement, the flow field of light scattering tracer particles is illuminated by a uniform light sheet. Usually, the light source is a laser, whose beam is guided by a triangular prism and a cylindrical lens. The thickness of the light sheet is about 
$1-2 \mathrm{~mm}$ and the light intensity is adjusted to render the tracer particles clear enough to be photographed.

\section{3 PHOTOGRAPHING}

The images of particle motions following the fluid flow are recorded by various highresolution cameras (CCD). In general, accurate velocity measurements require a short time interval $\Delta \mathrm{t}$ between two consecutive images. The optical axis of the camera lens must be perpendicular to the plane of the light sheet. However, it is difficult to set up the camera precisely. Hence, the camera should be calibrated to determine its parameters before photographing.

\section{4 IMAge Processing}

Image processing is the most important stage in a PIV measurement. First, the images that record the motion of the particles are transmitted to an $\mathrm{A} / \mathrm{D}$ converter to obtain digital images. Then, the digital images are processed. The processing includes removing noise, smoothing, converting the gray-scale images to binary images, labeling the particles, and calculating the center of gravity coordinates of the particles. Then, the coordinates of the particles are transferred from the image plane to the physical plane. Finally, the particle velocity vectors are calculated by various methods.

Fundamentals of PIV (Principles of twocomponent PIV (2C-PIV)):

Based upon the definition of velocity, i.e. the first derivative of position with respect to time, the technique consists in measuring the displacement of fluid $(\Delta \mathrm{x})$ over a given time interval $(\Delta t)$. The position of the fluid is imaged through the light scattered by liquid or solid particles illuminated by a laser light sheet. In most applications, such particles are not naturally present in the flow which, therefore, has to be seeded with tracer particles, assumed to be sufficiently small and light to move with local flow velocity. Figure 1 shows a typical standard twocomponent PIV (2C-PIV) setup. A plane within the flow is illuminated twice by means of two superimposed laser light sheets. The light scattered by the particles is recorded on two separate frames on a special crosscorrelation CCD camera sensor. For evaluation, the digital PIV recording is divided in small areas called "interrogation windows".

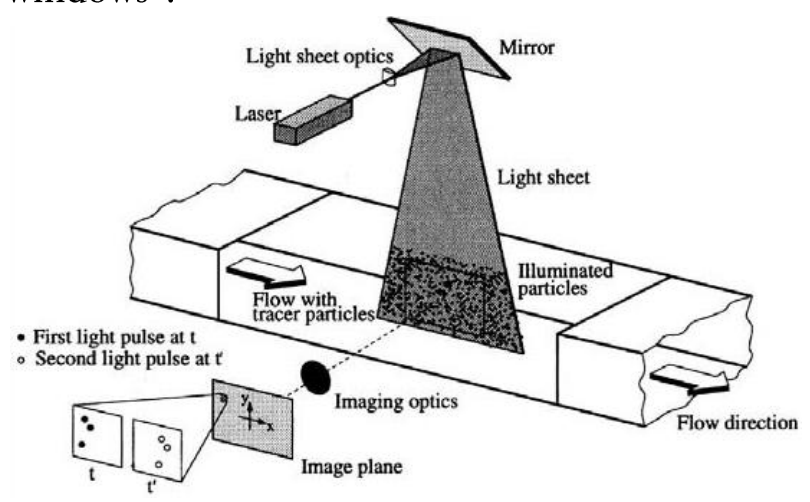

Fig. 1. A typical standard two-component PIV (2C-PIV) setup

The local 2C-displacement vector of the particle images between the two illuminations is determined for each interrogation window by means of a spatially statistical crosscorrelation function. Given the time interval between the two laser pulses and the image magnification obtained from camera calibration, the projection of the local flow velocity vector onto the plane of the light sheet, attributed to the center of the interrogation window, can then be deduced. Neighboring interrogation windows can be partially overlapping in order to reduce the spacing between two vectors in the resulting vector grid. In standard PIV, though several types of laser sources are suitable, the most commonly used is the pulsed Neodyme-YAG (Nd:YAG) laser, doubled in frequency $(532$ $\mathrm{nm})$. Pulse duration is typically $5-10 \mathrm{~ns}$, and repetition rate is on the order of $10 \mathrm{~Hz}$. Laser 
energy can reach $400 \mathrm{~mJ} /$ pulse. PIV systems are made of two independent laser cavities, but the laser beams should be superimposed in the near- and far-fields so that the two laser sheets illuminate the exact same area. In most cameras, digital image recording is done via a CCD (Charge-Coupled Device) sensor which converts photons to an electric charge based on the photoelectric effect. The CCD sensor consists of many individual sensors that are arranged in a rectangular array. Each pixel has a size on the order of $10 \times 10 \mu \mathrm{m}$. Their repetition rate in PIV double frame mode is on the order of $10 \mathrm{~Hz}$ [35].

The major asset of the PIV technique is its capacity to deliver a quantitative and instantaneous measurement of the velocity not only at one point, like Laser Doppler Velocimetry, but over a whole plane simultaneously: both visualization and quantification of the $2 \mathrm{D}$ flow structure become available. This, together with advances in electronic imaging and computing tools, explains its success over the past two decades [35].

\section{CLASSIFICATION OF PIV}

The current PIV techniques are classified here by type according to the principles of flow velocity calculation after image processing. The techniques of PIV are classified and their principles of velocity measurement are explained and introduced as follows:

\section{1 Path Line Method}

The velocity of motion of a particle is determined from the exposure time, photographing time, and particle image positions on pictures, which are taken by a multiple exposure technique. A popular technique called "path line method" measures the velocity by dividing the particle path line length by the exposure time [38-40].

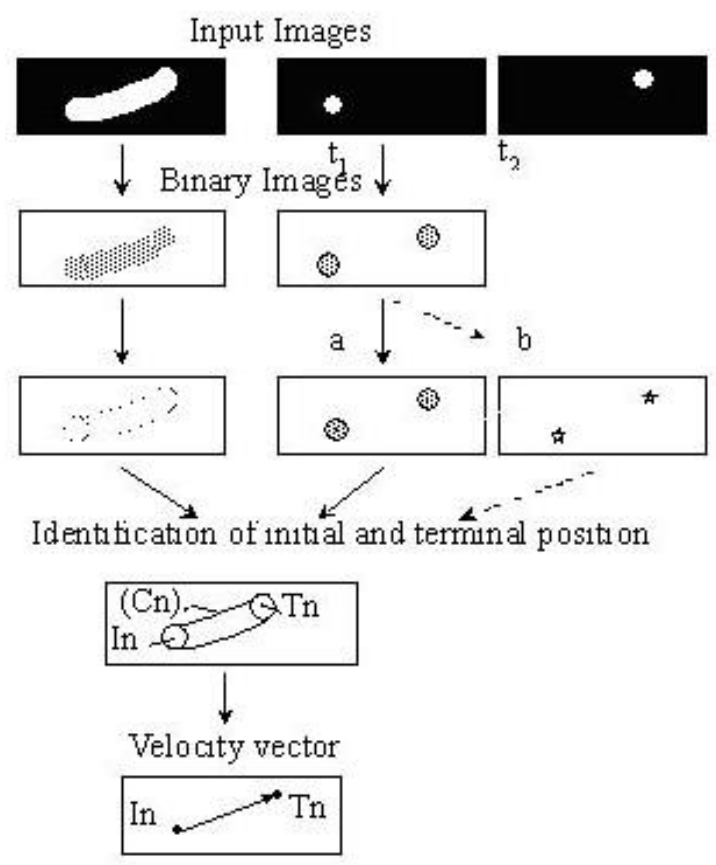

Fig. 2. Method of particle identification (Independent photographing technique of start and end points and pathline)

Using such a simple path line technique, the start and the end points of the velocity vectors cannot be decided. In order to solve the problem of the flow direction, other techniques using velocity information [41], brightness difference at the start and the end points [42], color information [43], recorded lighting at a short interval independent photography of the start and end points and the path line [44] etc, are introduced.

At its early stage, the path line method, which has a long history, was used to measure the length of a particle image path line and calculate the velocities of a visualized flow by hand. This method has been improved for automated measurement by introducing digital image processing but it is costly to determine the flow direction as shown in Fig. 2. Especially the direction ambiguity limits the application of this method to simple measurements of two-dimensional flows with low number densities of particles [45 and 46]. 


\section{2 STROBOSCOPE METHOD}

Particle motions are photographed using pulse type lighting by a stroboscope, i.e. dotted lines of particle images are recorded on a picture. The velocity is determined by the distance between the dotted images and the lighting pulse interval. To get satisfactory measurement accuracy, the distance between dotted images should be longer than ten times the size of a particle image. This method can be applied to low particle number density flow because of the difficulty of particle identification. This method extends for 3D distribution of three-component (3C) vorticity measurement in turbulent round jet liquids [47]. The accuracy of stereoscopic $\mu$ PIV was proven $[48,49,50,51$ and 52]. Wereley and Meinhart [53] gave an overview of particle image size at typical microscopy conditions. Stereoscopic microscopic Particle Image Velocimetry (stereo- $\mu$ PIV) was described in Lindken et. al [48 and 49]. Stereoscopic $\mu$ PIV measurements provide all three components of the velocity vector in a two-dimensional plane (of a finite thickness). A full $3 \mathrm{D}$ measurement is achieved by a scan in the direction normal to the measurement plane.

Dantec Dynamics made stereoscopic PIV software as an application example for stereoscopic PIV in an automotive wind tunnel to calculate $3 \mathrm{D}$ vectors based on the two 2D PIV vector maps and the (refined) camera calibration [54].

\section{Principles of stereoscopic PIV (3C-PIV):}

Adding a second camera to the setup, and arranging both cameras with different viewing axes, provides access to the otherwise unknown third component of the velocity vector, perpendicular to the laser light sheet and usually referred to as the out-of-plane component. This technique, known as stereoscopic PIV, can also reduce measurement uncertainty for the two in-plane components compared to a 2-C PIV setup, by accounting for the perspective projection caused by the displacement of the particles within the laser sheet thickness. Because what is measured when using only one camera is the projection of the local flow velocity vector onto one plane in the light sheet, the deduced displacement vector of the particle images results from two contributions: the in-plane displacement to be measured, but also the projection onto the plane of the out-of-plane component of velocity. In other words, the displacement of a particle animated with a purely out-of-plane velocity would be erroneously interpreted as a non-zero in-plane displacement. This error is unrecoverable, although potentially significant in a highly three-dimensional flow. By using two cameras with different viewing angles, projections of the velocity vector are obtained in two planes and in-plane can be differentiated from outof-plane displacements. Whenever space and optical access constraints allow, the usual practice is to install the cameras so that the opening angle between them approaches $90^{\circ}$, as in this configuration the measurement uncertainty for the out-of-plane component is minimum and similar to the uncertainty for in-plane components. In order to obtain a satisfying image quality toward the edges of the field-of-view, the lens principal axis should be aligned with the principal viewing direction when the viewing direction is different than $90^{\circ}$. To make sure that the complete image is in focus, the plane of the CCD sensor should be tilted according to the Scheimpflug criterion, in which the image plane, lens plane and object plane intersect in a common line. In practice, this is performed by mounting the camera on a so-called Scheimpflug adaptor, which allows it to rotate with respect to the lens. This optical 
arrangement has the side-effect of introducing a strong perspective distortion, which means that the magnification factor is no longer constant across the field-of-view. Therefore, the full spatial calibration matrix has to be determined for each camera. Quality of calibration is a key prerequisite for measurement reliability in stereoscopic PIV. The usual calibration procedure consists in taking several images of a flat calibration grid, placed first in the light sheet plane, then in a few other parallel planes. Based upon these images, a fit mapping function is computed for each camera and is used to dewarp raw particles images, i.e. to perform a backprojection in order to convert image coordinates into true "world" coordinates. Finally, the calibration data obtained from the calibration grid can be further improved to account for the slight residual misalignment of the calibration plate with respect to the light sheet. The principle of this method, often referred to in the literature as "selfcalibration", is to detect and correct small discrepancies between de-warped images recorded by the two cameras at the same time, which should contain identical information. Its implementation is based upon the computation of the cross-correlation function inside interrogation windows between these images (similarly to a standard PIV computation, which will be mentioned in later section "Computation of the crosscorrelation function"), which results in disparity vectors being brought iteratively to a near-zero value. Once calibration parameters have been determined for both cameras, two corresponding two-component vector fields can be computed from the de-warped images. The three velocity components can be deduced from these vector fields by solving a system of linear equations [35].
A reliable quantification of uncertainties is of prime importance for utilizing and interpreting experimental data, for PIV as much as for other metrological means. Numerous significant papers have already been published on this topic [55 and 56]; most of them focus on one particular cause of uncertainty, such as the presence of velocity gradients inside interrogation windows. Such studies are essential for selecting the best operating parameters to be implemented. Many experimental studies indicate a displacement uncertainty of 0.05-0.1 pixel; however, this uncertainty refers only to the determination of the position of the correlation peak through sub-pixel interpolation of the correlation data [35].

\subsection{LASER SPECKLE VELOCIMETRY METHOD (LSV)}

When a fluid flow is seeded with a high density of small particles, which are illuminated by a pulse type laser light sheet, random patterns of laser speckles result due to irregular interferences of the light scattered from the particles [58-60]. After double or multiple recording of the speckle patterns on the same film at a short interval and calculation of auto-correlation of the patterns, particle velocities and information of pattern movements are obtained. LSV utilizes Young's interference fringes formed by the scattered coherent light from particles in an interrogation spot [61] as shown in Fig. 3 and Fig. 4. Special high-concentration seeding is often needed to create speckle patterns [20]. A new dual beam sweep illumination technique has been developed and applied to measure flow velocities in an acrosol jet [59 and 60]. This dual-beam-sweep illumination is made by a beam splitter and a polygon mirror scanner for the measurement of a strongly unsteady high-speed flow with the LSV 
technique [62]. Additional procedures are usually necessary to determine the direction of particle motion. The laser speckle method has a great merit of good traceability of small particle motions in fluid flows and it is applicable to turbulent boundary layer flows, etc [ 45 and 46$]$.

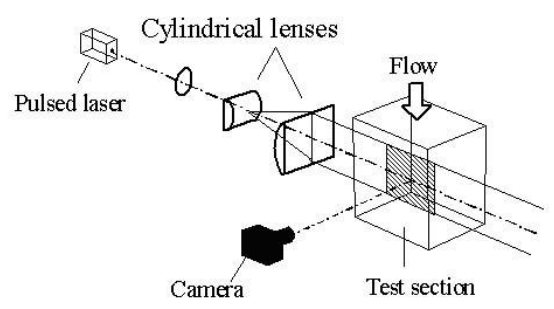

Fig. 3. Illumination and photographing system for specklegram

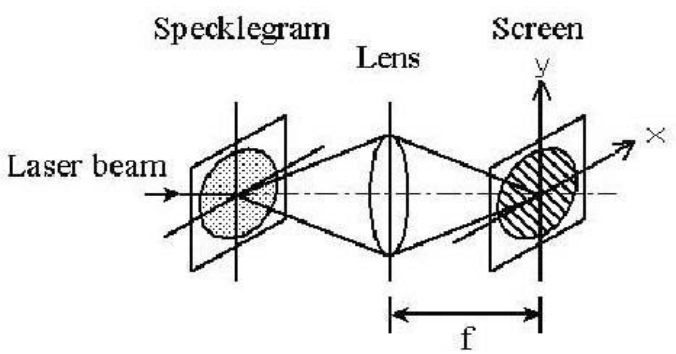

Fig. 4. Young fringe optical system for local velocity measurement

\subsection{BRIGHTNESS (OR CONCENTRATION) Distribution Pattern Cross-Correlation METHOD (BDCC)}

By tracking small local parts based on the highest similarity of spatial brightness (concentration) distribution patterns in two consecutive pictures visualized by small particles like smoke or dyestuff, velocities are calculated from the movement distances of the local parts and the time interval by using cross-correlation method [63-66]. The algorithm of particle brightness-distribution pattern tracking is the most popular one. As shown in Fig. 5, correct pairs of elements of particle clouds are obtained in two consecutive frames based on the similarity of image brightness distribution patterns in the two frames by calculating the values of the cross-correlation coefficient $\mathrm{C}_{\mathrm{fg}}$ defined by equation (1) or equation (2) [20].

$$
\begin{aligned}
& C_{f g}=\frac{\sum_{i=1}^{N} \sum_{j=1}^{M} f_{i j} g_{i j}}{\sqrt{\sum_{i=1}^{N} \sum_{j=1}^{M} f_{i j}^{2} \cdot \sum_{i=1}^{N} \sum_{j=1}^{M} g_{i j}^{2}}} \\
& C_{f g}=\frac{\sum_{i=1}^{N} \sum_{j=1}^{M}\left(f_{i j}-\bar{f}\right)\left(g_{i j}-\bar{g}\right)}{\sqrt{\sum_{i=1}^{N} \sum_{j=1}^{M}\left(f_{i j}-\bar{f}\right)^{2} \cdot \sum_{i=1}^{N} \sum_{j=1}^{M}\left(g_{i j}-\bar{g}\right)^{2}}} \\
& D_{f g}=\frac{1}{N M} \sum_{i=1}^{N} \sum_{j=1}^{M}\left(f_{i j}-g_{i j}\right)^{2} \\
& E_{f g}=\sum_{i=1}^{N} \sum_{j=1}^{M}\left|f_{i j}-g_{i j}\right|
\end{aligned}
$$

The similarity of image brightness distribution patterns can also be evaluated by the method of minimum quadratic difference $\mathrm{D}_{\mathrm{fg}}$, Gui and Merzkirch [67] defined by equation (3) or by the method of summation of brightness differences $\mathrm{E}_{\mathrm{fg}}$, Kaga et. al. [68] defined by equation (4). In these equations, $\mathrm{f}_{\mathrm{ij}}$ and $g_{i j}$ are digital gray values of the pixels in the overlapping interrogation windows of size $\mathrm{M} \times \mathrm{N}$ pixels which consist of elements of particle clouds in the two consecutive frames, $\bar{f}$ and $\bar{g}$ are mean values of brightness in the interrogation windows (Fig. 5). The pair is considered to be identified when the maximum value of $\mathrm{C}_{\mathrm{fg}}$, or the minimum values of $D_{f g}$ or $E_{f g}$ found for a pair of interrogation windows. The velocity of the particle clouds is computed as $\vec{v}=\vec{D}_{P Q} / \Delta t$ by using the displacement $\vec{D}_{P Q}$ of the cloud center from the coordinate $\mathrm{P}\left(\mathrm{x}_{\mathrm{i}}, \mathrm{y}_{\mathrm{i}}\right)$ to $\mathrm{Q}\left(\mathrm{x}_{\mathrm{j}}, \mathrm{y}_{\mathrm{j}}\right)$ and the time interval $\Delta t$ between the two frames. BDCC is widely used and can be applied for high number density images [45 and 46].

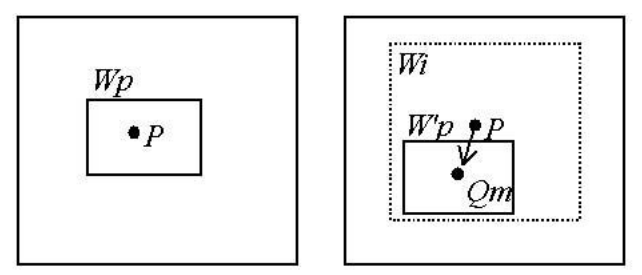

Fig. 5. Principle of cross-correlation method based on brightness distribution patterns. 
Wi stands the window of interrogation area. Wp stands the window of a reference pattern. The two figures stand for two consecutive images. $\mathrm{P}$ is the point where the velocity is to be calculated.

Computation of the cross-correlation function: The computation of the cross-correlation function forms the heart of most commercially available data processing software and is commonly based on FastFourier Transform (FFT) algorithms. Nowadays, most of them are iterative and based on an initial evaluation of velocity vectors using large interrogation windows, associated with a high SNR due to the large amount of particles taken into account in the statistics, but with poor spatial resolution. These velocity vectors and their gradients can then be used in the next step to adequately shift and deform the interrogation windows in each of the two exposures in order to reduce in-plane loss of correlated particle images. The interrogation window size is also progressively reduced to reach a final size of $32 \times 32$ or $16 \times 16$ pixels in practice, depending upon the density of particle images. Processing algorithms have been constantly developing with additional features aimed at enhancing signal-to-noise ratio (SNR) and removing spurious vectors. Recent efforts have mainly focused on improving spatial resolution by using adaptive interrogation windows parameters (size, shape, orientation).
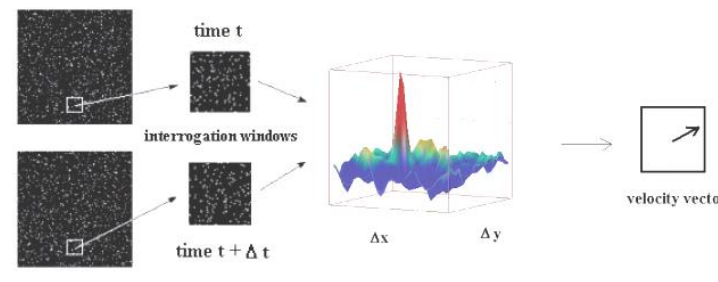

Fig. 6. Cross-correlation of a pair of two singly exposed recordings

In particular, R. Theunissen et al. [69] reported, for cases when the interest lies in the mean flow field, an original scheme based upon statistical adaptivity, i.e. taking into account ensemble statistics over an entire image set. Pre-processing is usually applied to raw images prior to cross correlation computation in order to enhance contrast, reduce background noise (e.g. generated by particles deposits on windows), or homogenize particle intensities in order to avoid the bias of the cross-correlation function towards large particles. Following vector computation, post-processing operations are used to remove spurious vectors. Fig. 6 shows the cross-correlation of a pair of two singly exposed recordings [35].

\subsection{Minimum QUADRATIC DIFFERENCE (MQD)}

MQD is a method for tracking ensembles of particle images of a digital PIV record by making use of the minimum quadratic difference (MQD) technique. This allows the application of the tracking principle to a much higher number of particle densities than single-particle tracking methods. This method is based on the principle of minimizing the (quadratic) differences between multicomponent vectors or matrices in order to investigate the degree of similarity existing between such vectors or matrices. This principle is frequently used as a tool for analyzing or minimizing errors of numerical approximations or mathematical statistics equation (3). The MQD tracking method can be applied to both PIV double exposures and consecutive single exposures that are evaluated traditionally by auto- and cross-correlation, respectively. The MQD tracking method is more accurate than auto- or cross-correlation methods. This method has good tracking properties and allows reasonable computation [45].

\section{6 Absolute Gray LeVEL DifferenCe METHOD USING SuCCESSIVE ABANDONMENT AlgorithM}

This method was proposed by Kaga et. al. [64]. The advantage of this method is that its computation is faster than the gray level cross- 
correlation method. In this method the summation of the absolute values of brightness differences is used to investigate the degree of similarity existing between patterns equation (4). The successive abandonment algorithm uses the $\mathrm{F}$ examination method (which is a statistical method) to eliminate the lower degrees of similarity under a certain threshold. This method has fair tracking and computation properties.

\section{7 Gray Level Auto- Correlation Method}

The principle of this method is to calculate the auto-correlation coefficient in the image obtained by multiplex exposures. The displacement value can be obtained by the local maximum value of the auto-correlation coefficient. In the nth-times multiplex exposure image, (2n-2) peak points appear symmetrically around the original point. When $\mathrm{n}$ increases, the value of the autocorrelation coefficient becomes lower. It is therefore difficult to detect the peak points. In this case a multiple (double) exposure method is used because it has a good performance. More than triple exposure methods cannot be used.

The advantage of this method is that it is applicable to a rapid flow. By using this method, the maximum measurable velocity is limited by the time interval between the images. Therefore, it requires a high-speed camera and a recording device to measure rapid flows. The auto-correlation method is in fact applicable to rapid flows because it is easy to get an exposure interval of a few nanoseconds $\left(10^{-12}\right)$ by using a pulse generator. The disadvantage of this method is the inability in determining the direction of the displacement; therefore additional methods are needed like the image shift technique [20], or the triple exposure technique [70 and 71].

\subsection{Binary Image Cross-Correlation Method (BICC)}

BICC is another kind of technique that employs an algorithm of particle distribution pattern tracking as shown in Fig 7. The motion of each particle is tracked based on the highest similarity of particle distribution patterns in two-consecutive binary pictures visualized by small particles. The particle velocity is calculated from the displacement (movement distances) of the particle center between the two consecutive frames and the time interval, by using a cross-correlation method (based on the pattern matching of particle clusters between two consecutive binarized images) [72 and 73]. This method is called binary image cross-correlation method (BICC), and uses binarized images of two consecutive frames for high-speed calculations. The computation of the cross-correlation value given by equation (1) can be simplified according to an exact mathematical discussion as follows:

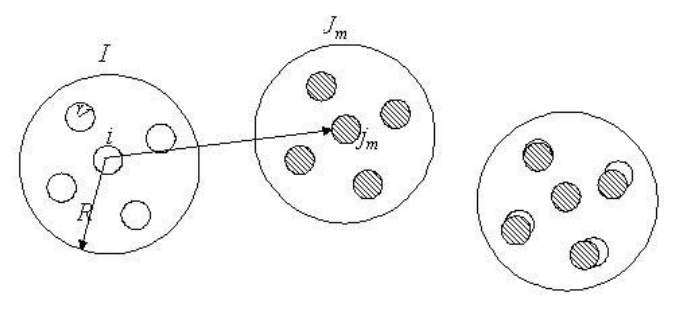

Fig. 7. Principle of binary image cross-correlation method.

The images on the left show two separated patterns of particles, and the image in the right shows the two patterns overlapped. Here the radii of all particles are assumed to be the same.

$C_{f g}=\frac{L}{\sqrt{n m}}$

where $\mathrm{L}$ is the summation of logical products of the image brightness binarized with the value of 1 or 0 at each pixel in two overlapping interrogation windows for two consecutive frames, $\mathrm{m}$ and $\mathrm{n}$ are the numbers of bright pixels in the first and the second 
window, respectively. The computation time of equation (5) is much shorter than that of equation (1) or equation (2). Therefore, the method of BICC is widely used and provides a real time measurement of the velocity field flow. This method has good tracking but it is limited to the case of low number densities of particles.

\section{9 Delaunay Tessellation Technique (DT- PTV)}

Another method of particle distribution pattern tracking is the so-called Delaunay tessellation technique [46 and 74], which also uses two consecutive binarized images. An example of the Delaunay tessellation is shown in Fig. 8.

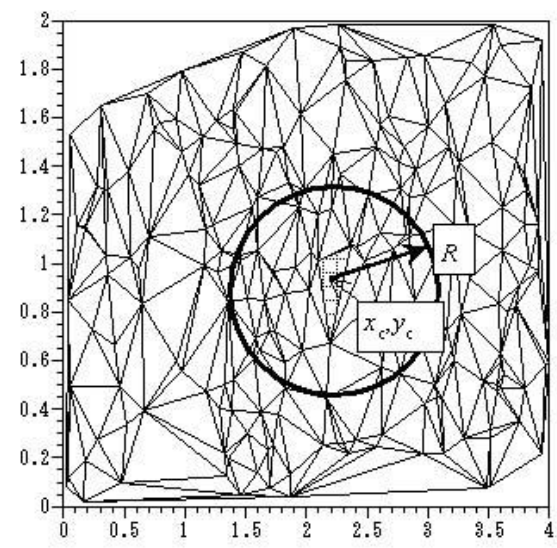

Fig. 8. The triangular net is generated by Delaunay tessellation

Particle tracking is performed by tracking each triangle.

The similarity of the two Delaunay triangles consisting of three centroids of particle images in each of the two pictures instead of interrogation windows is evaluated by the following equation:

$$
C_{f g}=\frac{\text { Area }(A \cap B)}{\sqrt{\text { Area }(A) \cdot \operatorname{Area}(B)}}
$$

Where Area $(A \cap B)$ stands for the overlapping area of the triangles $A$ and $B$, Area $(A)$ is the area of triangle $A$, and Area (B) is that of triangle $\mathrm{B}$. This technique has much higher speed performance than the method of BICC, and can obtain information of fluid rotation and translation velocities. Spurious vectors, which appear in the pattern tracking methods, can also be more effectively decreased by the technique of the Delaunay triangle. However, computation work for this method is extremely large when it is extended to the measurement of three-dimensional flows.

\section{10 SPRING MODEL}

Particle distribution patterns constructed by centroid locations of neighboring particles around a target particle are compared in two consecutive frames and their similarity is evaluated by calculating stresses in an imaginary spring system which connects the neighboring particles as shown in Fig 9. Information about fluid rotations can also be obtained by this technique and fewer spurious vectors are found. A three-dimensional technique of the spring model has already been developed. This method, which was developed by Okamoto [75] has good tracking and fast computation properties and is also suitable for shear flows.

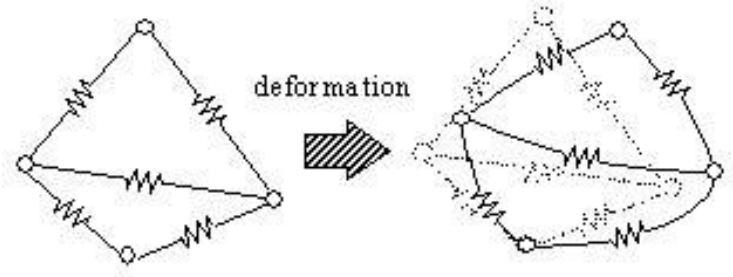

First Image

Second Image

Fig. 9. Spring Model

\section{11 The Velocity Gradient Tensor Method (VGT)}

The method of the velocity gradient tensor [76] is a new technique to analyze not only translations but also general fluid deformations such as rotation, shear, expansion and compression (Fig. 10). The minimum value of a sum of squared particle distances for two consecutive overlapping frames is used to identify particle pairs in the 
particle pattern tracking. The evaluating formula of particle distances is derived from Taylor series including the velocity gradient tensor reflecting shear, rotation and expansion in the fluid motion. This method is applicable to the case of low particle number density and has a good tracking and fast computation properties.

$$
E_{i j k}=\sum_{k=1}^{n} d_{i j k}{ }^{2}=\sum_{k=1}^{n}\left\|\begin{array}{l}
\left(x_{J}-x_{I}\right)-\left(x_{j k}-x_{i k}\right)+\|^{2} \\
\delta u\left(x_{I}\right)\left(x_{i k}-x_{I}\right) \Delta t
\end{array}\right\|^{2}
$$

Simultaneous dual-plane PIV experiments which utilized three cameras to measure velocity components in two differentially separated planes were performed in stream wise-span wise planes in log region of turbulent boundary layer at moderate Reynolds number (Re-1100) [77].

A two- frequency dual-plane stereo particles image velocimetry (DSPIV) technique was described for highly resolved measurement of the complete nine- component velocity gradient tensor fields on the quasi-universal intermediate and small scales of turbulent flows [78, 79, 80 and 81].

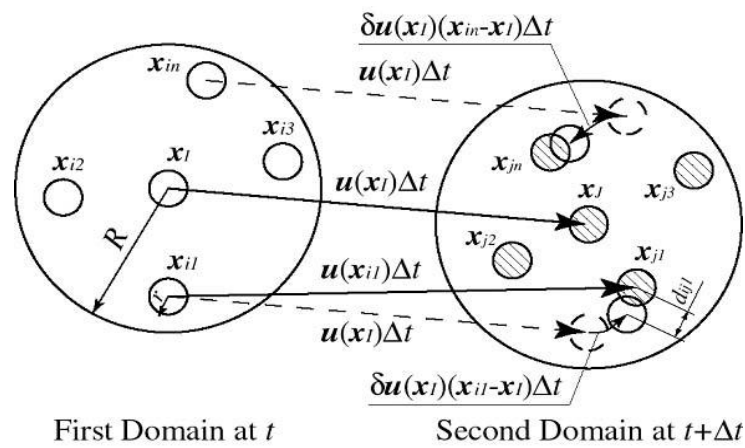

Fig. 10. Schematic diagram of the velocity gradient tensor method

3. 12 Four Consecutive Time Step Particle TRACKING Velocimetry (PTV)

This method is based on Particle Trajectory Tracking, which is frequently called Particle Tracking Velocimetry (acronym PTV) [82, 83, 84 and 85]. Using four consecutive pictures of flows visualized by tracer particles, which are photographed at short time intervals, each particle is tracked and identified and then the velocities of particles are calculated from the particle movement distances and the time interval. This method [42, 65, 66, 86 and 87] identifies each particle by investigating whether each trajectory of particle motion in the sequence is smooth or not. Therefore, the principle of the trajectory tracking algorithm is based on evaluating the smoothness of a particle trajectory. A method for evaluating the smoothness employs the change in the direction of a particle trajectory in two consecutive frames [82]. The other evaluates the deviation of combined changes in particle displacement and direction in four consecutive frames [83], as shown in Fig. 11. This method identifies particle pairs by calculating the evaluation function $\sigma_{t}$ with the following equations:

$\sigma_{t}=\sqrt{\frac{\sigma_{l}^{2}}{d_{m}^{2}}+\sigma_{\theta}^{2}}$

where:

$$
\begin{aligned}
& d_{m}=\frac{1}{3}\left(d_{i j}+d_{j k}+d_{k l}\right), \theta_{m}=\frac{1}{2}\left(\theta_{i k}+\theta_{j l}\right) \\
& \left.\sigma_{l}=\sqrt{\frac{1}{3}\left(\left|d_{i j}-d_{m}\right|^{2}+\left|d_{j k}-d_{m}\right|^{2}+\left|d_{k l}-d_{m}\right|^{2}\right.}\right) \\
& \left.\sigma_{\theta}=\sqrt{\frac{1}{2}\left(\left|\theta_{i k}-\theta_{m}\right|^{2}+\left|\theta_{j l}-\theta_{m}\right|^{2}\right.}\right)
\end{aligned}
$$

With $\mathrm{x}_{\mathrm{i}}, \mathrm{x}_{\mathrm{j}}, \mathrm{x}_{\mathrm{k}}$ and $\mathrm{x}_{\mathrm{l}}$ regarded as the coordinates of the same particle in four consecutive frames when the value of $\sigma_{t}$ is minimized. There is a third algorithm, which evaluates the changes in acceleration in four consecutive frames [84]. When the particle number density is so low that the spacing between particles is large compared with the displacements of the particles between exposures, the pairs of images are easily recognized and any special algorithm for trajectory tracking is no longer necessary. This is the simplest case for particle identification in the PIV technique [85]. The method of PTV provides a possible technique for threedimensional measurements and can decrease 
spurious velocity vectors. Spurious vectors may appear in the velocity vector field of PIV measurements due to mis-matching of particle pairs. In this case, the measurement accuracy and reliability are decreased. Therefore, some proposals such as detection and removal of spurious vectors, and replacement of spurious vectors by correct ones have been made [ 88 , 89, 90, 91 and 92]. In order to decrease and eliminate spurious vectors, first, noise signals should be excluded in the process of image recording by controlling illumination, seeding and recording devices carefully. Secondly, noise should be removed during the image processing of calculating brightness, coordinates, area and centroids of particle images. Finally, spurious vectors in the measured velocity vector field should be removed. A method for the removal of spurious vectors has been proposed by [73 and 74]. This method is based on the principle that spurious vectors do not satisfy the continuity equation of fluid flow.

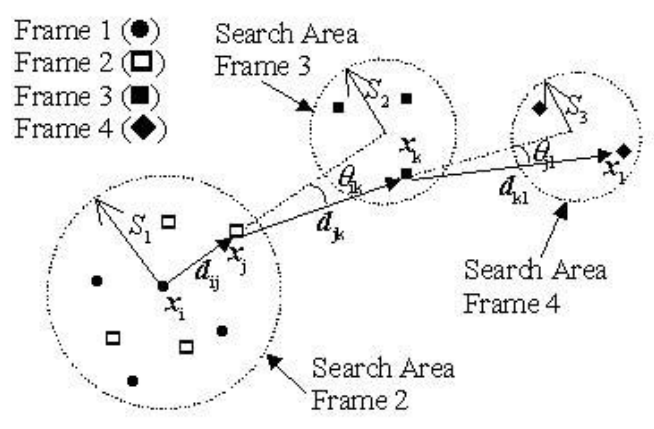

Fig. 11. Schematic diagram of the 4-PTV algorithm

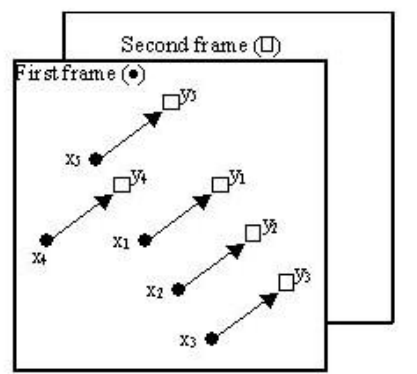

Fig. 12. Schematic diagram of VVH and 2-PTV

\subsection{VVH and Two-Frame Particle Tracking VELOCIMETRY 2-PTV}

This method uses the concept to match the probability between two consecutive image frames to obtain an instantaneous 2dimensional velocity field. This method for correctly tracking particle paths from only two image frames is based on the iterative estimation of match probability and nonmatch probability as a measure of the matching degree [82].

It is well known that in the case of the PTV method, the centroid of each particle image has to be determined in the image frame. Given such discrete points from each of two sequential images captured at different times, the next step is matching each particle image position in the first image with its corresponding position in the second image.

This matching problem procedure is also known as the correspondence problem, which can be solved by analyzing the optical flow in the images. The optical flow is a distribution of apparent velocities of the brightness pattern in an image. The 2-PTV method is a form of disparity calculations that may be used not only for optical flow calculations, but also for stereo matching or tracking applications. The computation time of this method is relatively short compared to that of the 4-frame PTV method. Additionally, this method recovers more velocity vectors and has a higher dynamic range and a lower error ratio [46]. Three-dimensional micro particle tracking velocimetry $(3 \mathrm{D}-\mu \mathrm{PTV})$ as described in $[48$, 93], but with only two cameras. Dracos [84 and 93] recommends at least 3 cameras, but measurements with only two cameras are possible at lower seeding density. 


\subsection{TOPOGRAPHIC PARTIClE IMAGE VELOCIMETRY \\ Recent advances in PIV}

Time-Resolved PIV

The technological limits of PIV have been pushed further into the distance by the still ongoing progress in laser technologies and electronic imaging systems. In particular, the new high repetition rate lasers and cameras available today have led to the development of time-resolved PIV (often referred to as TRPIV in the literature). Some high-speed cameras available today, based on CMOS (Complementary Metal Oxide Semiconductors) sensors, can reach a repetition rate of more than $80 \mathrm{kHz}$ (with a resolution reduced to $256 \times 256$ pixels), i.e. a PIV repetition rate of more than $40 \mathrm{kHz}(2$ images per PIV acquisition). The major drawback of these cameras with respect to standard PIV CCD cameras is a larger pixel size, slightly less than $20 \times 20 \mu \mathrm{m}$, but this difference has been significantly decreased in recent camera models. TR-PIV systems are currently limited by laser energy: a few $\mathrm{mJ} /$ pulse at $10 \mathrm{kHz}$ for a high-speed $\mathrm{Nd}$ :YLF laser, versus up to $400 \mathrm{~mJ} /$ pulse at tens of $\mathrm{Hz}$ for a Nd:YAG laser used in standard PIV (see Figure 13). In addition, high-speed laser pulse widths increase with repetition rate and range between 100 and 300 ns: this is much higher than the 5-10 ns pulse width of a Nd:YAG laser, and can be a severe limitation when investigating high-speed flows. Despite these drawbacks, the

recent success of TR-PIV systems can be explained by the jump in time resolution from the Hertz to the kilohertz range that they provide. One particular PIV hardware system can also be used in a broad frequency range, typically from 1 to $10 \mathrm{kHz}$ : as the product of repetition rate and energy per pulse stays roughly constant over the operating range, this offers some flexibility for finding the best compromise between energy and repetition rate based upon the experimental constraints. Technological progress is so fast that, according to some researchers [94], TR-PIV could replace standard PIV in a few years. Time-resolved PIV has opened the way to quantitative

measurement of velocity fields for unsteady flows or transient phenomena, which is a requirement for validating computation codes $[9,10]$. Until now, the highest operating (i.e. with sufficient energy per pulse) repetition rates of high-speed lasers have been limited to $20 \mathrm{kHz}$, which is borderline for resolving the smallest time scales of turbulence in many practical flows: Laser Doppler Velocimetry (up to several tens of $\mathrm{kHz}$ repetition rate) is still the most suitable optical diagnostic technique for accessing such information. However, this could change in the very near future, as highest available repetition rates have kept increasing very fast recently.

Tomographic Particle Image Velocimetry is a recently-developed technique for measuring the fully $3 \mathrm{D}$ velocity field within a volume of fluid, using a pulsed laser to illuminate particles in the fluid. The scientific community is increasingly using tomographic PIV, which is the only instantaneous measurement technique allowing the capture of a complete velocity field. Images from multiple cameras (typically 4 high-speed digital cameras) are reconstructed to give a $3 \mathrm{D}$ intensity field, containing bright regions where particles are present. A windowed cross-correlation is then used (between two successive reconstructions) to determine the displacement of particles in a time $\mathrm{dT}$. The windows are arranged on a regular grid within the volume, yielding a fully $3 \mathrm{D}$ velocity field within that volume. 
A relative new approach is tomographic PIV [95 and 96], where a reconstruction of the measurement volume by means of tomographic algorithms is done. Similar to PTV many cameras are needed to acquire the positions of the particles in space [97].

The process consists of two computationally intensive tasks - firstly, the tomographic reconstruction then the windowed crosscorrelation Fig. 14 shows a sample of fluid structures in a $3 \mathrm{D}$ region of fluid, measured with Tomographic PIV.

The working principle of tomographic-PIV is schematically represented in Fig. 13. Tracer particles immersed in the flow are illuminated by a pulsed light source within a 3D region of space. The scattered light pattern is recorded simultaneously from several viewing directions using CCD cameras similar to stereo-PIV, applying the scheimpflug condition between the image plane, lens plane and the mid-object-plane. The particles within the entire volume need to be imaged in focus, which is obtained by setting proper $\mathrm{f} /$ \#. The $3 \mathrm{D}$ particle distribution (the object) is reconstructed as a $3 \mathrm{D}$ light intensity distribution from its projections on the CCD arrays. The reconstruction is an inverse problem and its solution is not straightforward since it is in general underdetermined: a single set of projections can result from many different 3D objects. Determining the most likely 3D distribution is the topic of tomography [98], which is addressed in the following section. The particle displacement (hence velocity) within a chosen interrogation volume is then obtained by the $3 \mathrm{D}$ cross-correlation of the reconstructed particle distribution at the two exposures. The cross-correlation algorithm is based on the cross correlation analysis with the iterative multigrid window (volume) deformation technique extended to 3D [99].
The relation between image (projection) coordinates and the physical space (the reconstruction volume) is established by a calibration procedure common to stereo PIV. Each camera records images of a calibration target at several positions in depth throughout the volume.

The calibration procedure returns the viewing directions and field of view. The tomographic reconstruction relies on accurate triangulation of the views from the different cameras. The requirement for a correct reconstruction of a particle tracer from its images sets the accuracy for the calibration to a fraction of the particle image size. Therefore, a technique for the a-posteriori correction for the system misalignment can significantly improve the accuracy of reconstruction [81 and 100]. The mapping from physical space to the image coordinate system can be performed by means of either camera pinhole model [101] or by a third-order polynomial in $\mathrm{x}$ and $\mathrm{y}$ [102].

Tomographic particle image velocimetry (Tomo-PIV) is a technique for threecomponent three-dimensional (3C-3D) velocity measurement based on the tomographic reconstruction of a volume intensity field from multiple two-dimensional projection. As such the performance and accuracy of this technique is highly dependent on the algorithm used for reconstruction. Four different tomographic reconstruction algorithms were presented by C. H. Atkinson and J. Soria [103], namely multiplicative algebraic reconstruction technique (MART); adaptive algebraic reconstruction technique (AART); improved iterative algorithm for sparse object reconstruction (IIASOR); and simultaneous iterative reconstruction technique (SIRT). Results indicated that the MART and AART algorithms provide considerably better particle field reconstructions for fewer iterations. 
Tomographic-PIV was introduced as a novel technique for $3 \mathrm{D}$ velocity measurements. The $3 \mathrm{D}$ particle distribution within a volume is reconstructed by optical tomography from $2 \mathrm{D}$ particle image recordings taken simultaneously from several viewing directions.

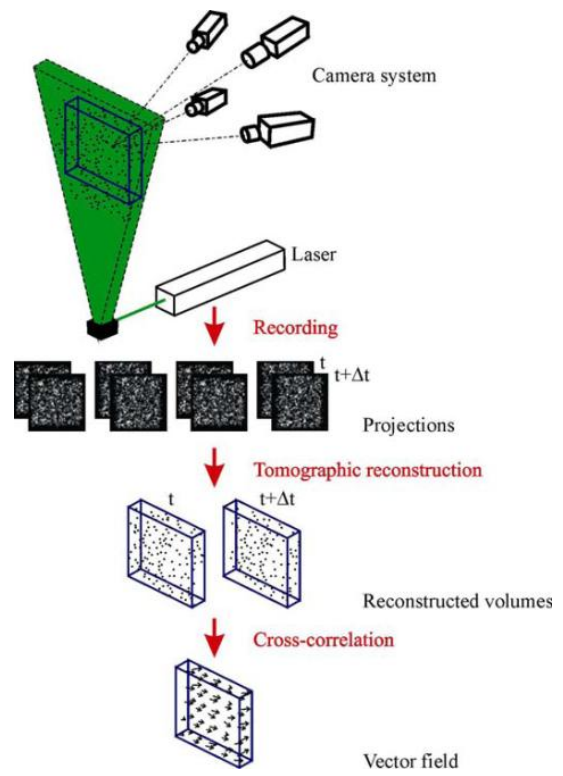

Fig. 13. Schematic Tomographic-PIV [104]

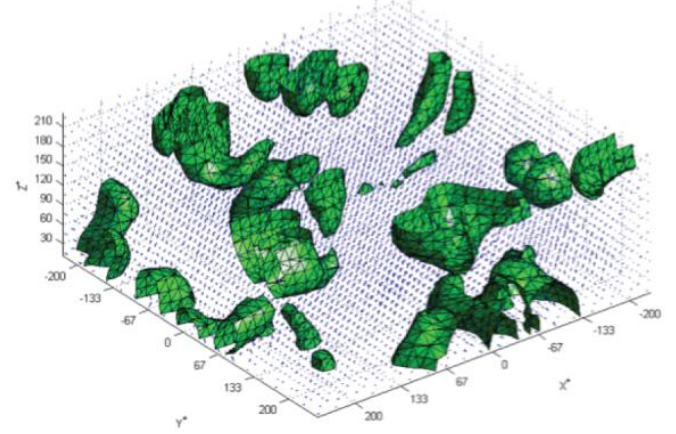

Fig. 14. Fluid structures in a 3D region of fluid, measured with Tomographic PIV

Velocity information results from 3D particle pattern correlation of two reconstructions obtained from subsequent exposures of the particle images. The technique makes use of digital imaging devices as opposed to holographic-PIV, and it allows a typical spatial resolution that is in between 3D-PTV (low seeding density) and scanning-PIV (high seeding density). Moreover, the technique measures the particle motion instantaneously in the $3 \mathrm{D}$ observation domain, which makes it suitable for the analysis of flows in several regimes and irrespective of the flow speed. A numerical simulation of a tomographic-PIV experiment showed that the multiplicative algebraic reconstruction techniques (MART) are the most suited to particle reconstruction returning distinct particles with limited artifacts. Furthermore, it was shown that the reconstruction algorithm converges to the desired solution for noise free particle image recordings. Based on a parametric study the number of cameras, viewing direction, particle density, calibration accuracy and image noise were identified as critical factors determining the quality of the $3 \mathrm{D}$ particle reconstruction. The calibration must be accurate within 0.4 pixel. Image pre-processing (e.g., removing background intensity) reduces the effect of random image noise. Adding a camera to the system provides extra information, which can be used to increase measurement resolution (increasing the particle density) or accuracy. A $3 \mathrm{D}$ simulation of a ring vortex flow showed that the 3D measurement configuration with four cameras can yield $66 \times 66 \times 10$ vectors in a $35 \times 35 \times 7 \mathrm{~mm}^{3}$ volume, with a typical measurement error of 0.1 pixels. The application of the technique to a turbulent cylinder wake flow at a Reynolds number $\operatorname{Re}_{\mathrm{D}}$ $=2700$, provided an experimental assessment of the capability of tomographic PIV. The measurement volume was aligned with the cylinder axis returning the streamwise evolution of the wake as well as its spanwise organization within a depth of one cylinder diameter $(8 \mathrm{~mm})$. The instantaneous velocity returned the Ka'rma'n street with counterrotating vortices alternatively shed and crosslinked by secondary vortex structures aligned in the streamwise-binormal direction. The results give a further confirmation that the tomographic-PIV technique is suited to the 
study of complex 3D flows [95, 96, 104 and 105]. Tomographic $\mu$ PIV as described by Elsinga et al. [95, 96], but with only two cameras. Elsinga et.al. [95] showed that the use of two cameras decreases the reconstruction accuracy.

A promising approach to capture the unsteady three-dimensional flow structures of large scale convective air flow was the recently developed Tomographic Particle Image Velocimetry (Tomographic PIV) [106 and 107].

A natural development of the PIV technique has been its extension to the third dimension in space, i.e. from a $2 \mathrm{D}$ planar to a $3 \mathrm{D}$ volumetric technique. Several different 3D techniques now exist: holographic PIV, scanning PIV, dual plane PIV, 3D PTV (Particle Tracking Velocimetry), defocusing PIV and, more recently, tomographic PIV [95. 96, 106 and 107]. This latter technique is a very powerful one compared to the others, that offers the simultaneous advantages of being fully volumetric, truly instantaneous and based on fully digital data recording and analysis. It is based on an extension of the stereoscopic PIV concept by using the principle of tomographic volume reconstruction. The 3D light intensity field of the illuminated particles is reconstructed for each voxel (the 3D equivalent to a pixel) from the images of typically four cameras viewing from different angles, by using a tomographic reconstruction algorithm. The entire volume is kept in focus by using a relatively small lens aperture (typically f-numbers > 8) and applying the Scheimpflug condition as mentioned in Principles of stereoscopic PIV. The particle displacement (hence velocity vector) within an interrogation volume is then obtained by the $3 \mathrm{D}$ cross-correlation of the reconstructed particle distributions at the two exposures. Combining TR-PIV hardware under a tomographic PIV arrangement leads to time-resolved tomographic PIV, which is used to obtain what ultimately most fluid mechanics researchers look for: a full sequence showing the time-resolved evolution of the three-component velocity vectors inside a volume. A. Schr öder [108] is a particularly good illustration of this technique's potential. It enabled the researchers to carry out for the first time a topological investigation of the flow structures in a turbulent boundary layer, within a temporally and spatially highly resolved Lagrangian and Eulerian frame [35].

Thermal convection is one of the most common natural types of flow and can be found e.g. in the atmosphere of the earth or in the sun. Moreover, many technical applications like the climatisation of residential buildings or passenger compartments of vehicles and aircraft are governed by convective air flow [106, 107 and 109]. Convective flow often occurs on large scales and tends to be organized in time dependent three-dimensional flow structures. In many cases convective flow is difficult to scale [110]. Thus, for accessing such flow experimentally methods for measuring the instantaneous three-dimensional velocity fields at full scale are needed. Recently, various optical non-intrusive measurement techniques have been developed and adapted by several research groups to measure large scale convective air flow with high spatial resolution. These techniques comprise methods like Particle Tracking Velocimetry (PTV), [111 and 112], Particle Streak Velocimetry (PSV) [113, 114, 115 and 116], and Particle Image Velocimetry (PIV) [117, 118 and 119], whereas each method has specific advantages and drawbacks.

Originally PTV, PSV and PIV are applied to measure the velocity distribution in thin light sheet planes. Thereby PIV provides the 
highest spatial resolution of the velocity data as compared to PTV and PSV and the possibility to measure instantaneous flow fields. In the last years different attempts have been made in order to extend PTV and PSV for measuring velocity fields in a volume [111, $112,113,114,115$ and 116], which is promising for convective air flow, if the threedimensional large scale flow structures are of interest.

An even more promising approach to capture the unsteadiness and three-dimensionality of the flow is the recently developed Tomographic Particle Image Velocimetry (Tomographic PIV), [104 and 105]. Applying this method the velocity field in a volume is obtained by correlating the three-dimensional intensity distribution of illuminated tracer particles at slightly different times.

Prior to the correlation, the intensity distribution in the volumes is prior reconstructed from its projections by means of tomography. Until now this technique is used only for measurement volumes of the order of ten cubic centimeters [104 and 105]. This measurement technique is adapted to large scale applications in order to measure the flow at full model size. When applying Tomographic PIV an important factor for the quality of the obtained velocity field is the accuracy of the calibration as mentioned by [104, 105 and 120]

Elsinga et al. [104 and 105] stated that the error in the mapping function, which transforms the world coordinates to image coordinates, should be smaller than 0.4 pixel. However, a calibration error of maximal 0.1 pixel should be aspired in order to significantly improve the quality of the reconstructed velocity field [120]. Hence, to study the feasibility of Tomographic PIV for large scale applications means to prove that the calibration error does not exceed this value.
This is done by applying the technique in a test set-up to a measurement volume of 0.69 $\mathrm{m} \times 0.42 \mathrm{~m} \times 0.24 \mathrm{~m}$, which is more than 1000 times larger than in previous applications that can be found in the literature [104-107].

In general the measurement parameters like low particle image density and high particle diameter are advantageous for 3D- $\mu$ PTV compared to correlation methods, but the small viewing angle of the imaging system also reduces the accuracy. The elongated reconstructed particle images results in erroneous velocity calculations for the 3Dcorrelation-based tomographic $\mu$ PIV [48].

HPIV and IPIV:

Besides the PIV systems, Holographic PIV (HPIV) [121-124] and Image-shifting PIV (IPIV) [125], both of which are optical methods, have made an important contribution to the modern fields of flow measurement.

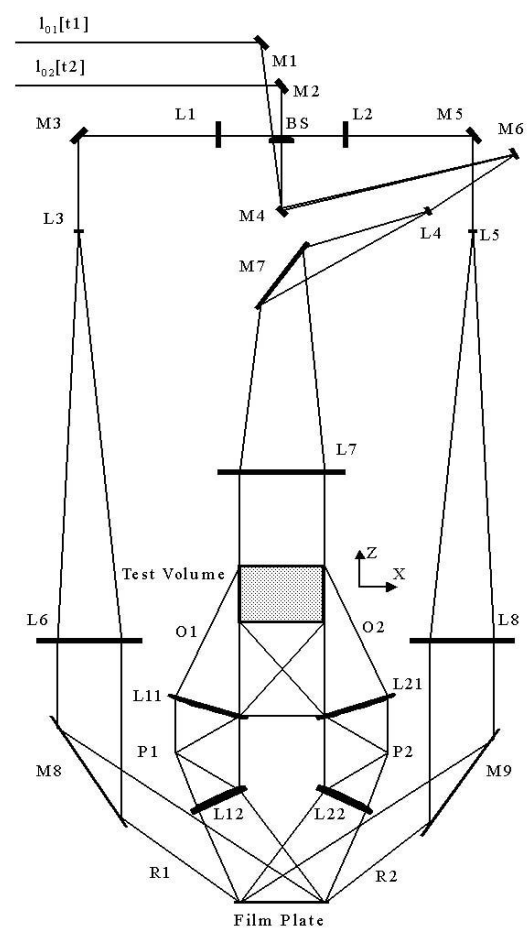

Fig. 15. A typical layout of HPIV

HPIV shown in Fig. 15 can track millions of particles in three-dimensional space, which 
are much more than the several hundred particles seeded in other PIV techniques. The particle size for HPIV and IPIV must be restricted to a few microns to avoid overloading the fluid. An advanced algorithm is proposed to process larger set of data in HPIV at a higher speed than the crosscorrelation methods [123]. IPIV techniques are especially effective for high-speed flows, which demand short time intervals of the order of a few microseconds between exposures. This may overcome the demerit of high-framing-speed video techniques, which drastically impair the spatial resolution in the PIV recordings. The most widely used imageshifting method adopts a rotating mirror system [125]. An IPIV system including a high-speed rotating mirror system is used at the Institut fur Stroemungsmechanik, Goettingen. It permits shift velocities exceeding $500 \mathrm{~m} / \mathrm{s}$ without any noticeable reduction in the optical quality of the images [46].

\section{THE APPLICATIONS OF PIV TO MULTIPHASE FLOW}

PIV which is based on digital image processing measurement of tracer particle motions dispersed in a fluid is one of the most effective methods to measure multidimensional flow because the detailed flow structure in the measurement field can be analyzed automatically by computer processing of the images. Recently, many scientific studies all over the world have recognized the availability of PIV for engineering research on fluid flow, so that various types of PIV measurement systems have been proposed for practical use. When image processing techniques are applied to the measurement of bubbly flow, a lot of information can be obtained simultaneously, e.g., two phase velocity field, bubble size and shape, turbulence energy, fluctuation scale and etc. For instance, even a single bubble rising in a still liquid shows irregular and complex behavior such as zig-zag motion or spiral motion. When many bubbles are rising in a volume, an extremely complicated twophase turbulent flow structure is generated by strong mutual interactions between bubbles and vortices. In such a case, even an engineer with rich experience cannot obtain all available technical information to improve the device only by eye observation. However it is necessary to comprehensively assess the detailed data of the flow structure in order to optimize the system design because it is obvious that the flow structure affects the total performance of various systems afore mentioned. The tool, which can answer and match this requirement, is PIV.

Nowadays, computer simulation of flows including bubbles has attracted attention both for commercial technical use and in academic research. This is because when we need to simulate or elucidate bubbly flow behavior, we must construct high level computational models to predict complicated behavior, based on conservation laws, constitutive equations and certain calculation methods.

Multiphase flow parameters besides velocities of fluid, bubbles and particles, void fraction in gas-liquid flows, particle concentration in gassolid and liquid-solid flows can be extracted by the PIV techniques. An example is simultaneous velocity measurements of both components of a gas-liquid two-phase flow by PIV [11-15, 18, 21 and 22]. This process contains a separation treatment of overlapping deformable bubbles and liquid drops with edge detection [126 and 127], and also describes how to separate the images between tracer particles and bubbles (drops and particles) in multiphase systems $[11-15,18$ and 45]. A PIV measurement of the threedimensional distribution of the void fraction 
in a bubble plume flow was reported by Murai et. al. [128]. Particle number flow rates were also investigated by Yamamoto et. al. [129 and 130]. Moreover, A PIV measurements were also applied for bubbly two-phase (gas-liquid) flow in order to measure a single rising bubble and its surrounding fluid field, void fraction, bubble size, bubble motion, liquid motion, surface flow induced by a bubble plume, the flow pattern of a bubble plume, and the flow pattern in a two stratified liquid flow by Hassan [11-18].

\section{SUMMARY AND CONCLUSION}

PIV has been developed rapidly with the recently noticeable development of computers and image processing techniques. The technique of PIV gives information on flow velocity, temperature and density through image analysis of visualized images of various types of flows. Unlike the traditional pointmeasurement methods, it can measure the simultaneous whole flow field at fairly good accuracy. PIV including image processing method is recognized as powerful new techniques to measure and elucidate thermal and fluid engineering fields including multiphase flows, and it expands to measure complex flow structures like bubbly two-phase flow. And also an accurate computer prediction for the bubbly flow has become possible using recent quick advanced techniques for CFD research. By further development of these new research methods, a large improvement of conventional system using bubbly two-phase flow and a creation of new techniques for industrial and environmental devices are expected.

Due to the complexity of fluid motion phenomena and the difficulties involved in applying equations of motion to even the simplest of realistic situations, fluid dynamics relies heavily on experiment. Of course the Computational Fluid Dynamics (CFD) techniques provide a competitive solution to solve many kinds of flows, but the models and various schemes need extensive investigations to verify even now. PIV techniques based on image processing have important advantages over more conventional techniques both for industrial and laboratory applications. Although the field is still developing, the most important techniques have been developed successfully to measure many kinds of flows, including the multi-phase flow.

Because of its strong merits, the technique of PIV has been recognized as the most advanced flow velocimetry, and has rapidly become more and more popular in the whole world. The areas of application have been expanding, for example, to the measurement of turbulent flows, multiphase flows, internal flows of fluid machines, bioengineering, medical engineering, environmental engineering, energy engineering, development of new materials, sports science, life science, mechatronics, robotics and so on. Furthermore, PIV has been recognized as a powerful new measuring tool in thermal and fluid engineering fields including multiphase flows. In addition, the use of PIV has extended to determine the velocity fields in two and three-dimensional, two-phase fluid flows. PIV is therefore a promising and powerful tool to study the structure of flows. As a result it is made clear that the PIV technique can contribute to various improvements.

\section{ACRONYMS}

2C-PIV: Two-Component PIV.

3C-3D: Three-Component Three-Dimensional.

3C-PIV: Three Components PIV.

3D- $\mu$ PTV:Three-Dimensional Micro Particle Tracking Velocimetry.

AART: Adaptive Algebraic Reconstruction Technique. 
BDCC: Brightness Distribution Cross-Correlation Method.

BICC: Binary Image Cross-Correlation Method.

CAFV: Computer-Aided Flow Visualization.

CCD: Charge-Coupled Device.

CFD: Computational Fluid Dynamics.

CMOS: Complementary Metal Oxide Semiconductors.

CT: $\quad$ Computer Tomography.

DSPIV: Dual-Plane Stereo Particles Image Velocimetry.

DT-PTV: Delaunay Tessellation Technique.

FFT: $\quad$ Fast-Fourier Transform.

HPIV: Holographic Particle Tracking Velocimetry.

IASOR: Iterative Algorithm for Sparse Object Reconstruction.

IC: Internal Combustion.

IPIV: Image-Shifting Particle Tracking Velocimetry.

LDV: $\quad$ Laser Doppler Velocimetry.

LSV: $\quad$ Laser Speckle Velocimetry Method.

MART: Multiplicative Algebraic Reconstruction Technique.

MQD: Minimum Quadratic Difference.

PIV: $\quad$ Particle Image Velocimetry.

PTV: $\quad$ Particle Tracking Velocimetry.

SIRT: Simultaneous Iterative Reconstruction Technique.

SNR: Signal-to-Noise Ratio.

TR-PIV: Time-Resolved Particle Tracking Velocimetry. VGT: Velocity Gradient Tensor Method.

\section{REFERENCES}

[1] Adrian R. J. , TAM Report, No.817, UILUENG-96-6004, University of Illinois at UrbanaChampaign, 1996.

[2] Westerweel J., Theoretical Analysis of the Measurement Precision and Reliability in PIV. The 3rd International Workshop on PIV'99, Santa Barbara, CA, USA, Sept.. Pp. 9-14, 1999.

[3] Hui Li. , Particle Image Velocimetry Based on Wavelet Image Compression Technique. The 3rd International Workshop on PIV'99, Santa Barbara, CA, USA, Sept.. Pp. 477-482, 1999.

[4] G. P. Romano, S. Zincone. , Measurement in Turbulent Flows Using PTV. The Effect of Tracer Particles. The 3rd International Workshop on PIV'99, Santa Barbara, CA, USA. Pp. 539544, 1999.
[5] Haidn O. J., V. Schmidt, and J. Sender., Flow Visualization of Interacting Cryogenic Coaxial Jets. ILASS-Eurrope'98. Pp. 602-608, 1998.

[6] Wormell D. C., and Jl. Sopchak., A Particle Image Velocimetry System Using a High Resolution CCD Camera. Conference 2005Optical Diagnostics in Fluid and Thermal Flow, 1997.

[7] S. W. Lee and Y. Liu. , Investigation of Gas/ Particles Flows in a Gaseous Fluidized Bed Using Particles Image Velocimetry. The 3rd International Workshop on PIV'99, Santa Barbara, CA, USA, Sept.. Pp. 689-694, 1999.

[8] A. Dolfi-Bouteyre, B. Augere, M. Valla, D. Goular, D. Fleury, G. Canat, C. Planchat, T. Gaudo, C. Besson, A. Gilliot, J-P Cariou, O Petilon, J. Lawsondaku, S. Brousmiche, S Lugan, 1. Bricteux, B . Macq. (2009). Aircraft Wake Vortex Study and Characterisation with $1.5 \mu \mathrm{m}$ Fiber Doppler Lidar. Aerospace lab $\mathrm{n}^{\circ} 1$, December 2009.

[9] L. Jacquin. (2009). Scales in Turbulent Motions. Aerospace Lab No.1, December 2009.

[10] 0F. Dupoirieux. (2009). Optical Diagnostics Used at Onera to Characterize Turbulent Reactive Flows and to Validate Aero- and Rocket Engine Combustor Modelling. Aerospace Lab No.1, December 2009.

[11] Hassan Abdulmouti. Surface Flow Generation Mechanism Induced by Bubble Plume. Yanbu Journal of Engineering and Science (YJES). Second issue. PS-M02-28 (50-67). 2011.

[12] Hassan Abdulmouti. Bubbling Convection Patterns in Immiscible Two-phase Stratified Liquids. International Journal of Heat Exchangers (IJHEX). Vol. VII. No. 1. Pp. 123-143. ISSN 1524-5608. June 2006.

[13] Hassan Abdulmouti and Tamer Mohamed Mansour. The Technique of PIV and Its Applications. 10th International Congress on Liquid Atomization and Spray Systems (ICLASS2006). Aug. 27-Sept. 1. Kyoto, Japan. 2006.

[14] Hassan Abdulmouti and Tamer Mohamed Mansour. Bubbly Two-Phase Flow and Its Application. 10th International Congress on Liquid Atomization and Spray Systems (ICLASS2006). Aug. 27-Sept. 1. Kyoto, Japan. 2006.

[15] Hassan Abdulmouti, Yuichi Murai, Ohno Yasushi, Fujio Yamamoto. , Measurement of Bubble Plume Generated Surface Flow Using 
PIV, Journal of the Visualization Society of Japan. Vol. 21. No. 2. Pp. 31-37, 2001.

[16] Hassan Abdulmouti, The Flow Patterns in Two Immiscible Stratified Liquids Induced by Bubble Plume, The International Journal of fluid Dynamic. Vol. 6. Article 1, 2002.

[17] Hassan Abdulmouti (2002). Visualization of The Flow Patterns in Two Immiscible Stratified Liquids Due to Bubble Plume. The 10th International Symposium on Flow Visualization. Kyoto Japan. August 26-29, 2002.

[18] Hassan Abdulmouti, Visualization and Image Measurement of Flow Structures Induced by a Bubbly Plume, Ph. D. thesis, Fukui University, 2003.

[19] Yamamoto F., Iguchi M., Ohata J., Andrzej S.. , Fundamentals and Applications of ParticlesImaging Velocimetry (Focussing on Binary Image Cross-Correlation Method for 3-D PTV). Proceedings of Intentional Conference on Fluids Engineering at Chosun University. Nov. 1-2, Kwangju, Korea. Pp. 39-48, 1994.

[20] 0Adrian R. J. , Particle-Imaging Techniques for Experimental Fluid Mechanics, Annu. Rev. Fluid Mech., Vol. 23, pp. 261-304, 1991.

[21] Hassan Yassin A., Blanchat T. K., Seeley Jr., C. H. , PIV Flow Visualization Using Particle Tracking Techniques. Measurement in Science and Technology, Vol. 3, pp. 633-642, 1992 a.

[22] Hassan Yassin A., Blanchat T. K., Seeley Jr., C. H. and Canaan R. E. , Simultaneous Velocity Measurement of Both Components of a TwoPhase Flow Using Particles Image Velocimetry. Int. Journal of Multiphase Flow, Vol. 18, No. 3, pp. 371-395, 1992 b.

[23] Yamamoto F., Iguchi M., Ohata J., Koketsu M. , Measurement of Bubbling Two-Phase Flow Using 3-D PTV Based on Binary Image CrossCorrelation Method. FED-Vol. 209, Flow Visualization and Image Processing of Multiphase Flow System, Proceedings of the 1995 ASME/JSME Fluids Engineering and Laser Anenometry Conference and Exhibition August 13-18, pp. 131-136, 1995.

[24] Hilgers St., Merzkirch W., Particle Velocity and Particle Concentration in a Three- Phase Flow. Proceedings of the Sixth International Symposium on Application of Laser Techniques to Fluid Mechanics and Workshop on
Computers in Flow Measurements, July 20-23, pp. 9.1.1-9.1.4, 1992.

[25] Kasagi N., Nishino K. , Probing Turbulence with Three-Dimensional Particle-Tracking Velocimetry. Experimental Thermal and Fluid Science, Vol., 4, pp. 601-612, 1991.

[26] Moursali, E., Marie J. L., Bataille, J. , An Upward Turbulent Bubbly Boundary Layer Along a Vertical Flat Plate, 1995.

[27] Murai Y., Matsumoto Y. , Three Dimensional Structure of a Bubble Plume: Measurement of the Three Dimensional Velocity. FED-Vol. 209, Flow Visualization and Image Processing of Multiphase Flow Systems, Proceedings of the 1995 ASM/JSME Fluids Engineering and Laser Anenometry Conference and Exhibition August 13-18, 1995.

[28] Okley T. R., Loth, E., and Adrian R. J. , Cinematic Two- Phase PIV for Bubbly Flow. FED- Vol. 209, Flow Visualization and Image Processing of Multiphase Flow Systems, Proceedings of the 1995 ASM/JSME Fluids Engineering and Laser Anenometry Conference and Exhibition August 13-18, pp. 123-130, 1995.

[29] Sridhar G., Kata J. , Drag and Lift Forces on Microscopic Bubbles Entrained by a Vortex. Phys. Fluids, Vol. 7 No. 2, pp. 389-399, 1995.

[30] 0L. David and P. Gicquel - Evolutions de la technique PIV à travers quelques conférences internationales de 2000 à aujourd'hui. Congrès Francophone de Techniques Laser, CFTL 2006, Toulouse, France, September 19-22, 2006.

[31] M. Stanislas, J. Westerweel , J. Kompenhans Particle Image Velocimetry : Recent Improvements. Proceedings of the EUROPIV2 workshop held in Zaragoza, Spain, March 31, April 1, 2003.

[32] M. Stanislas , K. Okamoto , C.J. Kähler - Main results of the first international PIV Challenge. Measurement Science and Technology, Vol. 14, pp. R63-R89, 2003.

[33] M. Stanislas , K. Okamoto , C.J. Kähler , J. Westerweel - Main results of the second international PIV Challenge. Exp. Fluids, Vol. 39, pp. 170-191, 2005.

[34] M. Stanislas , K. Okamoto , C.J. Kähler , J. Westerweel , F. Scarano - Main results of the third international PIV Challenge. Exp. Fluids, Vol. 45, pp. 27-71, 2008. 
[35] C. Brossard, J.-C. Monnier, P. Barricau, F.-X. Vandernoot, Y. Le Sant, F. Champagnat, G. Le Besnerais (Onera 2009). Principles and Applications of Particle Image Velocimetry. Optical Diagnostics of Flows. The Onera Journal Aerospace Lab. Issue 1 - December 2009.

[36] Ruan X., Song X., F. Yamamoto, J. Lin. , PIV Measurement of Fluid Flow and Mixing Homogeneous Degree in Static Mixer, proceedings of the Second International Workshop on PIV'97-Fukui. Pp. 85-90, 1997.

[37] Yamamoto F., Uemura T., Tian H., and Ohmi K., Three-Dimensional PIV Based on Binary Cross-Correlation Method. JSME International Journal, Series b, Vol. 36, No. 2, pp. 279-284, 1993.

[38] Imaichi K. and Ohmi K. , Numerical Processing of Flow-Visualization Pictures-Measurement of Two-Dimensional Vortex Flow, J. Fluid Mech., 129, pp. 283-311, 1983.

[39] Takagi M. and Tomita T. , Measurement Processing of Flow Visualization, Proc. of the 11 th Images Processing Conference, 9, pp. 12-16, 1983.

[40] 0Kobayashi T. and Yoshitake Y. , Development of Digital Image Processing System for Path Line Picture, Trans. of JSME (B), 55-466, pp. 19661970, 1985.

[41] Dimotakis P. E., Dcbussy F. D. and Koochesfahani M. , Particle Streak Velocity Field Measurements in a Two-Dimensional Mixing Layer, Physics of Fluids, 24-6, pp. 995-999, 1981.

[42] Kobayashi T., Saga T., Segawa S. and Handa H. , Development of a Real-Time Velocimetry Measurement System for Two-Dimensional Flow Field Using a Digital Image Processing Technique, Trans. of JSME (B), 55-509, pp. 107-115, 1989.

[43] Fujiwara T., Nishihara S. and Hirose K., Color Flow-Visualization Photography and Digital Image Processing Techniques, Trans. of JSME (B), 53-493, pp. 2762-2770, 1987.

[44] Kobayashi T. , Development of a Flow Field Analysis System Using a Digital Image Processing technique, Report of Grant 1986-C for Scientific Research by the Japan Ministry of Education, 1988.

[45] Song X., Yamamoto F., Iguchi M., Koketsu M., Chen G. , 3-D PTV Measurement of Bubble
Rising Flow in Cylindrical Vessel. ISIJ Int., vol. 36, pp. 54-57, 1996.

[46] Song X. , The Development of PIV Technique and Its Application to the Investigation of Flow Structure in Bubbly Flow, Ph.D. thesis, Fukui University, 1999.

[47] Toshio Hori and Jun Sakakibara. (2004). HighSpeed Scanning Stereoscopic PIV for 3D Vorticity Measurement in Liquids. Measurement Science and Technology. Institute of Physics Publishing. Vol. 15 No. 6. 2004

[48] Ralph Lindken, Jerry Westerweel, Bernhard Wieneke, 3D micro-scale velocimetry methods: A comparison between 3D- $\mu$ PTV, stereoscopic $\mu$ PIV and tomographic $\mu$ PIV. 13th Int Symp on Applications of Laser Techniques to Fluid Mechanics Lisbon, Portugal, 26-29 June, 2006. Paper \#1099, 2006.

[49] Lindken R, Westerweel J, Wieneke B , Stereoscopic Micro Particle Image Velocimetry. Exp Fluids, online first, DOI: 10.1007/s00348006-0154-5, 2006

[50] 0Lindken R, Westerweel J, Wieneke B , Stereoscopic micro PIV applied to the threedimensional flow in a T-mixer. Proceedings of the PIVNET2 International Workshop on $\mu \mathrm{PIV}$ and Applications in Microsystems, Delft, the Netherlands, 2005a.

[51] Lindken R, Westerweel J, Wieneke B , Development of a stereoscopic micro Particle Image Velocimetry System (stereo- $\mu$ PIV) and first measurements of the three-dimensional flow structure in a T-micromixer. Proceedings of the Euromech Colloquium 472 on Microfluidics and Transfer, Grenoble, France, 2005b.

[52] Lindken R, Westerweel J, Wieneke B , Development of a Self-Calibrating Stereo- $\mu$-PIV System and its Application to the ThreeDimensional Flow in a T-Shaped Mixer. Proceedings of the 6th International Symposium on Particle Image Velocimetry, Pasadena, California, USA, 2005c.

[53] Wereley ST, Meinhart CD, Micron resolution particle image velocimetry. In: Breuer KS (Ed.), Microscale Diagnostic Techniques. Springer, 2005.

[54] Dantec Dynamics. A Stereoscopic PIV Software in an Automotive Wind Tunnel. Nova Instruments company, 2010. 
[55] B. Lecordier , M. Trinit é. (2006). Accuracy assessment of image interpolation schemes for PIV from real images of particle. 13th Int. Symp. on Applications of Laser Techniques to Fluid Mechanics, Lisbon, Portugal, June 26-29, 2006.

[56] J. Westerweel, On velocity gradients in PIV interrogation. Exp. Fluids, Vol. 44, pp. 831-842, 2008.

[57] J. Westerweel, Theoretical analysis of the measurement precision in particle image velocimetry. Exp. Fluids, Vol. 29, Nº, pp. S3S12, 2000.

[58] Kawahashi M. , Laser Speckle method, J. Of Visualization Society of Japan, 7-25, pp. 84-89, 1987.

[59] Kawahashi M. , Speckle Method in 3ed Lecture course text book, pp. 58-60, 1991.

[60] 0Kawahashi M., Dual-Beam-Sweep Laser Speckle Velocimetry, Exp. Fluids, 11 pp. 278-280, 1991.

[61] Simpkins PG; Dudderar TD , J. Fluid Mech., 89, pp. 665, 1978.

[62] Kawahashi M, Yamamoto K., Speckle Method Using Beam Scanning Technique. Proc. of the 1st Int. Workshop on PIV'95-Fukui, pp. 155-158, 1995.

[63] Kimura I., Kimura H. and Takamori T. , Image Processing of Flow around a Circular Culinder by Using Correlation Technique, Proc of 4th Int. Symposium on Flow Visualization, Hemisphere Pub. Corp., pp. 221-226, 1986.

[64] Sakakibara J. Takeda T., Kobayashi K., Hishida K. and Maeda M., Two-Dimension and Time Series Measurement of Thermally Stratified Shear Flow Using Correlation Technique, J. of The Visualization Society of Japan, 11-Suppl. No. 1, pp. 157-160, 1991.

[65] Kobayashi T., Sakakibara J., Hishida K. and Maeda M. , Time Series Measurement of Turbulent Flow Field Sing Image Processing System, ASME-FED, Vol. 128, pp. 155-162, 1991.

[66] Kobayashi T., Saga T. Haeno T. and Tsuda N., Development of a Real-Time Velocity Measurement System for High Reynolds Fluid Flow Using a Digital Image Processing Design, ASME-FED, Vol. 128, pp. 9-14, 1991.

[67] Gui L., Merzkirch W. , A Method of Tracking Ensembles of Particle Images. Exp. in Fluids, 21, pp. 465-468, 1996.
[68] Kaga A., Inoue Y., Yamaguchi K., Pattern Tracking Algorithm for Airflow Measurement Through Digital Image Processing of Visualization Images. J. of the Visualization Society of Japan, vol. 14, No. 53, pp. 38-45, 1994.

[69] R. Theunissen, F. Scarano, M.L. Riethmuller. (2008). Statistical adaptivity in PIV interrogation for mean flow estimation. 14th Int. Symp. on Applications of Laser Techniques to Fluid Mechanics, Lisbon, Portugal, 07 -10 July 2008.

[70] Uemura T., Iguchi, Vol. 13 SN2, pp. 125-130, 1993.

[71] Raffel M., Willert C., Kompenhans J., Particle Image Velocimetry. Springer-Verlag Berlin Heidelberg, 1998.

[72] Uemura T., Yamamoto F; Koukawa M. , High Speed Algorithm for Particle Tracking Velocimetry, Using Binary J. of the Visualization Society of Japan, 10-38, pp. 196-202, 1990.

[73] Yamamoto F., Wada A., Iguchi M., Ishikawa M., Discussion of the Cross-Correlation Methods for PIV. J. Flow Visualization and Image Processing. Vol. 3, pp. 65-78, 1996.

[74] Song X., Yamamoto F., Murai Y., Iguchi M., Cross-Correlation Algorithm for PIV by Delauay Tessellation Proc. of the 2nd Int. Workshop on PIV'97-Fukui, pp. 109-115, 1997.

[75] Okamoto K. , Three-Dimensional Particle Tracking Algorithm Velocity Vector Histogram and Spring Model. Proc. of the 1st Int. Workshop on PIV'95-Fukui, pp. 21-32, 1995.

[76] Ishikawa M., Yamamoto F., Murai Y., Iguchi M., Wada A., A Novel PIV Algorithm Using Velocity Gradient Tensor. Proc. of the 2nd Int. Workshop on PIV'97-Fukui, pp. 51-56, 1997.

[77] Bharathram Ganapa thisubramani. Ellen K. Longmire. Ivan Marusic. Stamatios Pothos. DualPlane PIV Technique to Determine the Complete Velocity Gradient Tensor in a turbulent Boundary Layer. (2005). Experiments in Fluids 39:222-231 DOI 10.1007/S00348-005-1019-z. Springer-Verlag 2005.

[78] John A. Mul lin, Werner J. A. Dahm. DualPlane Stereo Particles Image Velocimetry (DSPIV) for measuring velocity gradient fields at intermediate and small scales of turbulent flows. (2005). Experiments in Fluids 38:185-196 DOI 10.1007/S00348-004-0898-8. Springer-Verlag 2005. 
[79] Mullin JA, Dahm WJA, Dual-plane stereo particle image velocimetry measurements of velocity gradient tensor fields in turbulent shear flow. I. Accuracy assessments, Phys. Fluids 18, 2006 a.

[80] 0Mullin JA, Dahm WJA, Dual-plane stereo particle image velocimetry measurements of velocity gradient tensor fields in turbulent shear flow. II. Experimental results, Phys. Fluids 18, 2006 b.

[81] Wieneke B, Taylor S, Fat-sheet PIV with Computation of Full 3D-Strain Tensor using Tomographic Reconstruction. Proceedings of the 13th Int Symp on Applications of Laser Techniques to Fluid Mechanics, Lisbon, Portugal, Paper \#1064, 2006.

[82] Baek SJ., Lee SJ., A New Two-Frame Particle Tracking Algorithm Using Match Probability. Exp. in Fluids, 22, pp. 23-32, 1996.

[83] Nishino N., Kasagi N, Hirata M., ThreeDimensional Particle Tracking Velocimetry Based on Automated Digital Image Processing. Journal of Fluids Engineering, ASME, Vol. 111, pp. 384391, 1989.

[84] Malik NA., Dracos Th. Papantoniou DA., Particle Tracking Velocimetry in ThreeDimensional Flow. Exp. Fluids 15, pp. 279-294, 1993.

[85] Liu ZC., Adrian RJ., Particulate Two-Phase Flow, edited by M. C. Roco, ButterworthHeinemann, pp. 33, 1996.

[86] Tsuda N., Kobayashi T. and Saga T., Development of a Real-Time Measurement System for High Reynolds Fluid Flow Using a Digital Image Processing Technique, J. of the Visualization Society of Japan, 11 -Suppl. No.1, pp. 181-184, 1991.

[87] Tsuda N., Kobayashi T. and Saga T., Development of a General Use PIV System (Current), Proc. of 6th Osaka Symposium on Flow Measurement, pp. 47-52, 1991.

[88] Wernet MP., Pline A., Particle Displacement tracking technique and Cramer-Rao Lower Bound Error in Centroid Estimates From CCD Imagery. Exp. Fluids 15, pp.295-307, 1993.

[89] Westerweel J., Efficient Detection of spurious Vectors in Particle Image velocimetry Data. Exp. Fluids, 16, pp. 236-247, 1994.

[90] Huang HT., Fiedler HE., Wang J., Limitation and Improvement of PIV. Part I: Limitation of
Conventional Techniques Due to Deformation of Particle Image Pattern. Exp. Fluids 15, pp. 168174, .

[91] Huang HT., Fiedler HE., Wang J., Limitation and Improvement of PIV. Part II: Particle Image Distortion, A Novel Technique. Exp. Fluids 15, pp. 263-273, 1993 b.

[92] Veber P., Dahl J., Hermansson R., Exp. in Fluids, 22, pp. 482, 1997.

[93] Dracos, The Particle tracking in threedimensional space. In Th. Dracos, editor, Threedimensional velocity and vorticity measuring an image analysis techniques. Kluwer Academic Publishers, 1996.

[94] R. Hain , C. J. Kähler (2005). Advanced Evaluation of Time-Resolved PIV Image Sequences. 6th Int. Symp. on Particle Image Velocimetry, Pasadena, California, USA, September 21-23, 2005.

[95] G. E. Elsinga, F. Scarano, B. Wieneke, B.W. van Oudheusden. (2005 a). Tomographic particle image velocimetry. 6th International Symposium on Particle Image Velocimetry. Pasadena, California, USA, September 21-23, 2005.

[96] G. E. Elsinga, F. Scarano, B. Wieneke, B.W. van Oudheusden BW, Assessment of Tomo-PIV for three-dimensional flows. 6th Int. Symp on PIV, Pasadena, USA, 2005 b.

[97] Rainer Hain, Christian J. Kähler. , 3D3C TimeResolved Measurements with a Single Camera Using Optical Aberrations. 13th Int Symp on Applications of Laser Techniques to Fluid Mechanics Lisbon, Portugal, 26-29 June, 2006.

[98] Herman GT, Lent A , Iterative reconstruction algorithms.Comput Biol Med 6:273-294, 1976.

[99] Scarano F, Riethmuller ML, Advances in iterative multigrid PIV image processing. Exp Fluids 29:S51-S60, 2000.

[100]Wieneke B , Stereo-PIV using self-calibration on particle images. Exp Fluids 39:267-280, 2005.

[101]Tsai RY, An efficient and accurate camera calibration technique for 3D machine vision. In: Proceedings of IEEE conference on computer vision and pattern recognition, Miami Beach, FL, USA, pp 364-374, 1986.

[102] Soloff SM, Adrian RJ, Liu ZC , Distortion compensation for generalized stereoscopic particle image velocimetry. Meas Sci Technol 8:14411454, 1997. 
[103]C. H. Atkinson and J. Soria. (2007). Algebraic Reconstruction Techniques for Topographic Particle Image velocimetry. 16th Australasian Fluid Mechanics Conference Crown Plaza, Gold Coast, Australia. 2-7 December 2007.

[104]Elsinga GE, Scarano F, Wieneke B, van Oudheusden BW, Tomographic particle image velocimetry. Exp. Fluids 41:933-947, 2006.

[105]F. Scarano. (2006). Tomographie en PIV: nouveaux développements et perspectives en vélocimétrie tridimensionnelle résolue dans le temps. Congrès Francophone de Techniques Laser, CFTL 2006, Toulouse, France, September 19-22, 2006.

[106]Matthias Kühn, Klaus Ehrenfried, Johannes Bosbach, Claus Wagner., Feasibility Study of Tomographic Particle Image Velocimetry for Large Scale Convective Air Flow. 14th Int Symp on Applications of Laser Techniques to Fluid Mechanics Lisbon, Portugal, 07-10 July, 2008.

[107]Kühn M, Bosbach J, Wagner C., Systematic experimental parameter study of mixed convection in a passenger aircraft cabin mock-up. Submitted, 2008.

[108]A. Schr öder , R. Geisler , K. Staack , B. Wieneke , G.E. Elsinga , F. Scarano , A. Henning Lagrangian and Eulerian views into a turbulent boundary layer flow using time-resolved tomographic PIV. 14th Int. Symp. on Applications of Laser Techniques to Fluid Mechanics, Lisbon, Portugal, 07 -10 July 2008.

[109]Bosbach J, Penneçot J, Wagner C, Raffel M, Lerche T, Repp S, Experimental and numerical simulations of turbulent ventilation in aircraft cabins. Energy 31:694-705, 2006 a.

[110]Westhoff A, Grabinski N, Bosbach J, Wagner C, Thess A, Scaling of turbulent mixed convection under high pressure. Proc. 5th Int. Symp. on Turbulence And Shear Flow Phenomena, Garching, Vol. 2, 2007.

[111]Müller RHG, Scherer T, Rötger T, Schaumann O, Markwart M, Large body aircraft cabin a/c flow measurement by helium bubble tracking. J. Flow Visualization \& Image Processing 4: 195306, 1997.

[112]Resagk C, Lobutova E, Rank R, Müller D, Putze T, Maas HG, Measurement of large-scale flow structures in air using a novel 3D particle tracking velocimetry technique. Proc. 13th Int. Symp. on
Applications of Laser Techniques to Fluid Mechanics, Lisbon, 2006.

[113]Sun Y, Zhang Y, Development of a stereoscopic particle image velocimetry system for fullscale room airflow studies, Part II: Experimental setup. ASHRAE Transactions 109: 540-548, 2003.

[114]Sun Y, Zhang Y, Zhao L, Wang X, An algorithm of stereoscopic particle image velocimetry for fullscale room airflow studies. ASHRAE Transactions 110: 75-80, 2004.

[115]Sun Y, Zhang Y, Wang A, Topmiller JL, Bennett JS , Experimental characterization of airflows in aircraft cabins, Part I: Experimental system and measurement procedure. ASHRAE Transactions 111:45-52, 2005.

[116]Zhang Y, Sun Y, Wang A, Topmiller JL, Bennett JS, Experimental characterization of airflows in aircraft cabins, Part II: Results and research recommendations. ASHRAE Transactions 111:53-59, 2005.

[117]Müller RHG, Flögel H, Scherer T, Schaumann $\mathrm{O}$, Markwart M, Investigation of large scale low speed air conditioning flow using piv. Proc. 9th Int. Symp. on Flow Visualization, Edinburgh, 2000.

[118]Bosbach J, Kühn M, Wagner C, Raffel M, Resagk C, du Puits R, Thess A, Large scale particle image velocimetry of natural and mixed convection. Proc. 13th Int. Symp. On Applications of Laser Techniques to Fluid Mechanics, Lisbon, 2006 b.

[119]Bosbach J, Kühn M, Wagner C , Large scale particle image velocimetry with helium filled soap bubbles, 2007.

[120]Wieneke B , Volume self-calibration for stereopiv and tomographic-piv. Proc. 7th Int. Symp. on Particle Image Velocimetry, Rome, 2007.

[121] Meinhart CD., Prasad AK., Adrian RJ., A Parallel Digital Processing System for $<$ Particle Imaging Velocimetry Meas. Sci., and Tech. 4, pp. 619-626, 1993.

[122]Barnhart DH., Adrian RJ., Meinhart CD., Papan GC. , Phase-Conjugate System for Holographic Particle Image Velocimtery Through Thick Curved Windows. Proc. of the Int. Workshop on PIV-Fukui'95, pp. 1-6, 1995.

[123]Sheng J., Meng H. , A 3D Velocity Field Extraction Technique Using Genetic Algorithm. Proc. of the 2nd Int. Workshop on PIV'97-Fukui, pp. 43-50, 1997. 
[124]Meng H., Estevadeordal J., Gogineni S., Goss L., Roquemore WM. , Holographic Flow Visualization As A Tool For Studying 3D Coherent Structures and Instabilities. Proc. of the 2nd Int. Workshop on PIV'97-Fukui, pp. 27-34, 1997.

[125]Raffel M., Kompenhans J., Theoretical and experimental Aspects of Image Shifting by Means of a Rotating Mirror System for Particle Image Velocimetry. Meas. Sci. Tech., 6, pp. 795-808, 1995.

[126] Yamamoto F., Ruan X., Song X., Iguchi M , A Method for Counting Particle Number in Overlapped Particle Images, J. of the Visualization Society of Japan, 17, Suppl. No.2, pp. 107-110, 1997 a.

[127]Canny J. , A Computational Approach to Edge Detection. IEEE Trans. on Pattern Analysis and Machine Intelligence, vol. PAMI-8, No. 6, pp. 679-698, 1986.

[128]Murai Y., Watanabe S., Yamamoto F., Matsumoto Y. , Three-Dimensional Measurement of Bubble Motions in Bubbly Plume Using Stereo Image Processing. Proc. of the 2nd Int. Workshop on PIV'97-Fukui, pp. 1318, 1997.

[129]Yamamoto F., Iguchi M., Murai Y, Song X, Kato H. , Proc. of the Fifth Triennial Int. Symposium on Fluid Control, Measurement and Visualization, pp. 911, 1997 b.

[130]Yamamoto F., Song X. , Text book of JSME. No. 97-67, pp. 31-52, 1997. 
تقنية PIV (تمثيل سرعه الجزيئات "قياس السرعة بتتبع أثر الجزيئات") : مبادى و تطبيقات

\author{
حسان عبدالمعطي \\ جامعة الأمير محمد بن فهد، قسم الهندسة الميكانيكية، الملكة العربية السعودية
}

الملخص:

لوحظت الـ PIV كتقنية مفيدة و ضرورية جداً من أجل تحليل حقول الجريانات المعقدة ثنائية و ثلاثية الابعاد، و كذلك الجريانات ثنائية الأطو ار. تتعهة تقنية PIV بإعطاء نتائج منطورة كونها تزود حلاً مرئياً ذذلك بالأخذ بعين الإعتبار كامل الحقل الددروس، بالإضافة لذلك تقدم تقنية PIV عدة مميزات و خصائص لدراسة جريان السوائل. إن PIV تقنية قياس تسمح لنا بالحصول على سرعة الجريان للحقل بأكمله و ذلك بزمن قصير يصل لجزء من الثانية و لذلك أصبحت تقنية PIV الأكثر إنتشاراً و شهرة و امتدت بثكل سريع في العالم كونها لوحظت بأنها التقنية الأكثر تقدماً لقياس الجريان و ذلك بسبب خصائصها القوية.

تر اوحت تطبيقات هذه التقنية لتشمل قياس الجريانات المضطربة و الجريانات ثنائية الطوار و الجريانات الداخلية لميكانيك السوائل، كما استخدمت في الهندسة الحيوية و الهندة الطبية و هندة البيئة و هندة القوى و الطاقة و استخدمت في تطوير مو اد جديدة و في علوم الرياضة و في حياة العلماء و في الميكانيك و الالكترون و التحكم الألي و غير ها. و لأبعد من ذلك لوحظت تقنية PIV على أنها آلية القياس القوية الجديدة في علم التيرموديناميك و حقول هندسة السو ائل بما في ذلك الجريانات ثناية الأطو ار ـ كنتيجة تعتبر تقنية PIV الآلية القوية المستقلية لدراسة بنية الجريانات. في هذا البحث تم تخليص المبادئ و الطرق النموذجية المستخدمة لتقنية قياسات PIV ، كذلك تم شرح تصنيف طر ائق PIV. 